\title{
Los Pedregales (Lupiñén-Ortilla, Huesca): contribución al conocimiento del poblamiento altomedieval en la Hoya de Huesca ${ }^{1}$
}

\section{Los Pedregales (Lupiñén-Ortilla, Huesca): A contribution to the knowledge of the early medieval settlement system in Hoya de Huesca}

\author{
Jesús V. Picazo Millán ${ }^{2}$ \\ Dpto. de Ciencias de la Antigüedad, Instituto de Investigación en Ciencias \\ Ambientales (IUCA), Universidad de Zaragoza \\ Fernando Pérez-Lambán ${ }^{3}$ \\ Grupo de Investigación Consolidado Prehistoria (IT622-13), \\ Universidad del País Vasco / Euskal Herriko Unibertsitatea \\ José Luis Peña Monné ${ }^{4}$ \\ Dpto. de Geografía y Ordenación del Territorio, Instituto de Investigación en \\ Ciencias Ambientales (IUCA), Universidad de Zaragoza \\ $M^{a}$ Marta Sampietro \\ Laboratorio de Geoarqueología, Facultad de Ciencias Naturales, Universidad \\ Nacional de Tucumán-CONICET \\ Luis A. Longares Aladrén ${ }^{6}$ \\ Dpto. de Geografía y Ordenación del Territorio, Instituto de Investigación en \\ Ciencias Ambientales (IUCA), Universidad de Zaragoza \\ Julia Justes Floría ${ }^{7}$ \\ Área de Arqueología, Instituto de Estudios Altoaragoneses \\ Julián M. Ortega Ortega ${ }^{8}$ \\ Seminario de Arqueología y Etnología Turolense
}

\section{RESUMEN}

El conocimiento de la ocupación visigoda y paleoislámica en el valle del Ebro resulta un tanto difuso, más por falta de investigaciones y por la escasa visibilidad de los asentamientos, que por un efectivo despoblamiento. En este artículo presentamos los resultados de nuestras investigaciones en el

\footnotetext{
${ }^{1}$ Trabajo realizado gracias al apoyo del Grupo de investigación Paleoambientes del Cuaternario-PALEOQ de la Universidad de Zaragoza y del proyecto I+D+i HAR2012-36967 Dinámica de la ocupación prehistórica en el valle medio del Ebro durante el Holoceno Superior del Ministerio de Economía y Competitividad.

2 jpicazo@unizar.es http://orcid.org/0000-0002-4726-819X

${ }^{3}$ fernando.perezl@ehu.eus http://orcid.org/0000-0001-94596949

${ }_{4}^{4}$ jlpena@ unizar.es http://orcid.org/0000-0003-4067-8222

5 sampietro@tucbbs.com.ar http://orcid.org/0000-0002 7681-070X

${ }^{6}$ lalongar@unizar.es http://orcid.org/0000-0002-9558-1308

7 juliajustes@hotmail.com

8 saet@unizar.es
}

yacimiento de Los Pedregales, en la provincia de Huesca, un conjunto complejo en el que se encuentran materiales de diversas cronologías (romanos, altomedievales, modernos...) junto con numerosas estructuras pétreas en un área completamente alterada por procesos erosivos. Una minuciosa prospección y la excavación de algunas estructuras en el marco de un estudio geoarqueológico, nos ha permitido explicar la ocupación principal del yacimiento como un campo de silos datado entre los siglos VI y IX, que aporta una nueva referencia para la comprensión de los paisajes rurales antiguos y las comunidades campesinas dispersas que los ocupan. En el artículo se describen e interpretan las estructuras, se estudian los materiales más relevantes, especialmente los cerámicos, y se contextualiza el yacimiento con relación al poblamiento y los procesos históricos que afectan a este territorio.

\section{SUMMARY}

The Visigothic and Paleo Islamic settlement system in the Ebro Valley (NE Spain) is yet not well known. This is due to the lack of research and low visibility of the settlements, but not to an effective demographic recession. In this paper we present 
the results of our research in Los Pedregales archaeological site, in Huesca Province. The site appears as a complex assemblage of archaeological artifacts from different chronologies (Roman, Early Middle Ages, Modern...) and numerous stone structures in a severely eroded terrain. Within the framework of a geoarchaeological research, we carried out an intensive surface survey and the excavation of some of the structures. Thus, we interpret the main phase of the site as an assemblage of storage pits dated between the $6^{\text {th }}$ and the $9^{\text {th }}$ Centuries AD. This is new data for the improvement of our understanding of past rural landscapes and the scattered peasant communities that dwelled in them. In this paper, we describe and interpret the studied structures, we study the most relevant artifacts recovered - mainly pottery - and we set the site in the context of the general settlement system and historical processes that affect this territory.

PALABRAS CLAVE: Visigodo; islámico; poblamiento rural; silos; cerámicas; valle del Ebro; geoarqueología.

KEY WORDS: Visigoth; Islamic; rural settlement; storage pit; pottery; Ebro Valley; Geoarchaeology.

\section{INTRODUCCIÓN}

El estudio de los sistemas de poblamiento altomedievales, la configuración de los espacios agrarios y su evolución, constituye una problemática para la que obligatoriamente se hace necesario el aporte de la Arqueología, tanto en su vertiente territorial como ambiental, y representa una línea de investigación abordada y demandada por medievalistas que trabajan en diferentes ámbitos geográficos (Quirós 2009, Laliena 2010, Vigil-Escalera 2013b...). De especial interés y dificultad resulta la transición del mundo tardorromano al musulmán (cfr. Salvatierra 2015), periodo relativamente desconocido en el valle del Ebro, circunstancia que, como recoge Rodríguez (2014: 321) haciéndose eco de las opiniones de otros especialistas (cfr. Hernández y Bienes 2003, Laliena 2010), no parece achacable a un supuesto despoblamiento sino a la carencia de investigaciones arqueológicas. Por ello la incorporación de datos concretos, muchos de ellos registros arqueológicos difusos, difíciles de identificar y de estudiar debido a su escasa perceptibilidad en el paisaje, pero que denotan la importancia y generalización de un poblamiento rural disperso, suponen aportaciones de interés para la comprensión de esas comunidades y su evolución en un periodo en el que persiste cierto déficit de información. De hecho, muchos de los trabajos más recientes y relevantes en este campo derivan de proyectos de gestión patrimonial ligados a la construcción de infraestructuras que obligan a la realización de prospecciones intensivas y excavaciones de cierta amplitud (Rodríguez 2014; Frangin et alii 2014), estrategias que, no sin problemas (cfr. Vigil-Escalera 2013a: 142), están poniendo de relieve los elusivos registros que parecen caracterizar estos momentos.

En este sentido creemos que Los Pedregales, situado en la Hoya de Huesca, es un buen ejemplo de ese tipo de yacimientos y puede aportar nuevos datos de interés para la caracterización de esas comunidades rurales y su evolución en el contexto del Ebro Medio. Pero además, este sitio representa un buen ejemplo

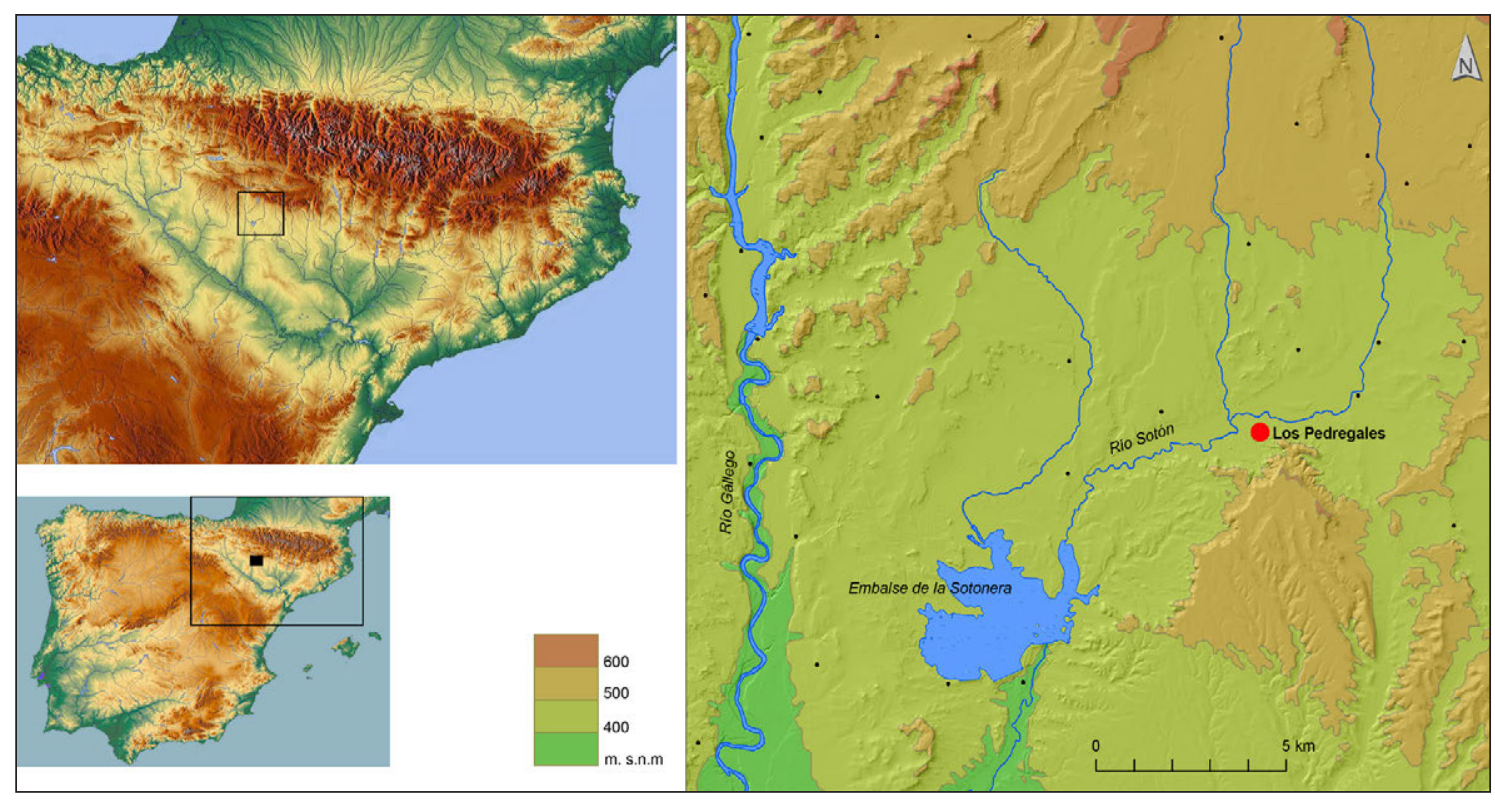

Figura 1. Situación del yacimiento. 


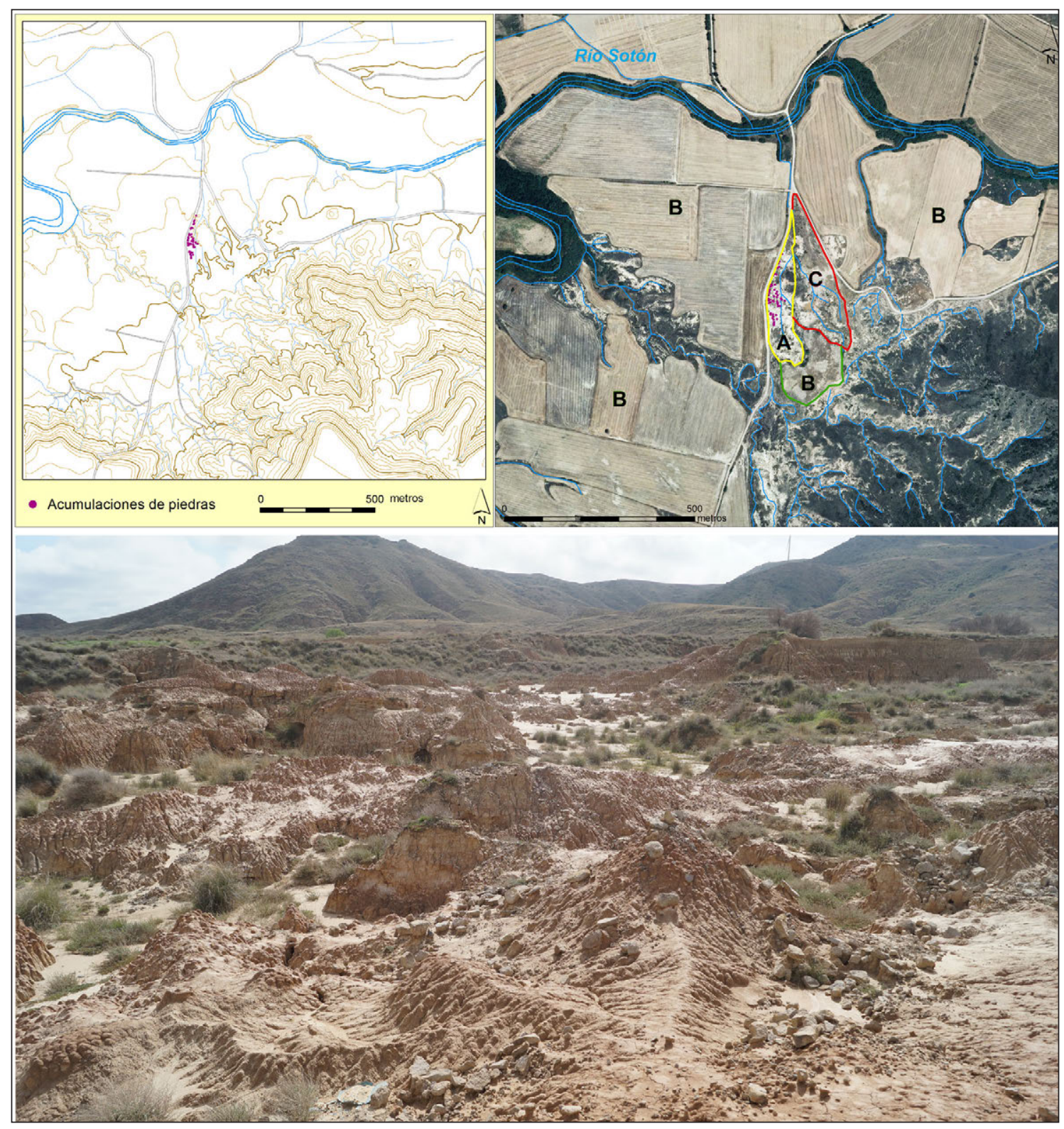

Figura 2. Detalle de situación de Los Pedregales y vista parcial del yacimiento desde el sector noroeste. Fotografía aérea (PNOA vuelo 2012, IGN): A- Zona de badlands con restos arqueológicos. B- Superficie conservada del cono del barranco. C- Zona de badlands afectada por vertidos de basura y extracciones de áridos.

de los procesos erosivos más recientes que no sólo están desmantelando rápidamente el propio yacimiento, sino que transforman y, en ocasiones modifican de forma radical los rasgos de los espacios agrarios, constituyendo un buen referente para el estudio de los cambios ambientales de naturaleza climática y/o antrópica que caracterizan las etapas finales del Holoceno y que justificaron nuestra intervención inicial en este lugar.
De acuerdo con tal planteamiento, en este artículo pretendemos presentar un nuevo yacimiento que puede contribuir al conocimiento de las comunidades campesinas que caracterizan esas etapas, su implantación en el territorio y los procesos de continuidad que parecen experimentar. A la vez supone una llamada de atención acerca de las dificultades que plantea el reconocimiento de este tipo de sitios ante la alteración que presenta el registro arqueológico en contextos 


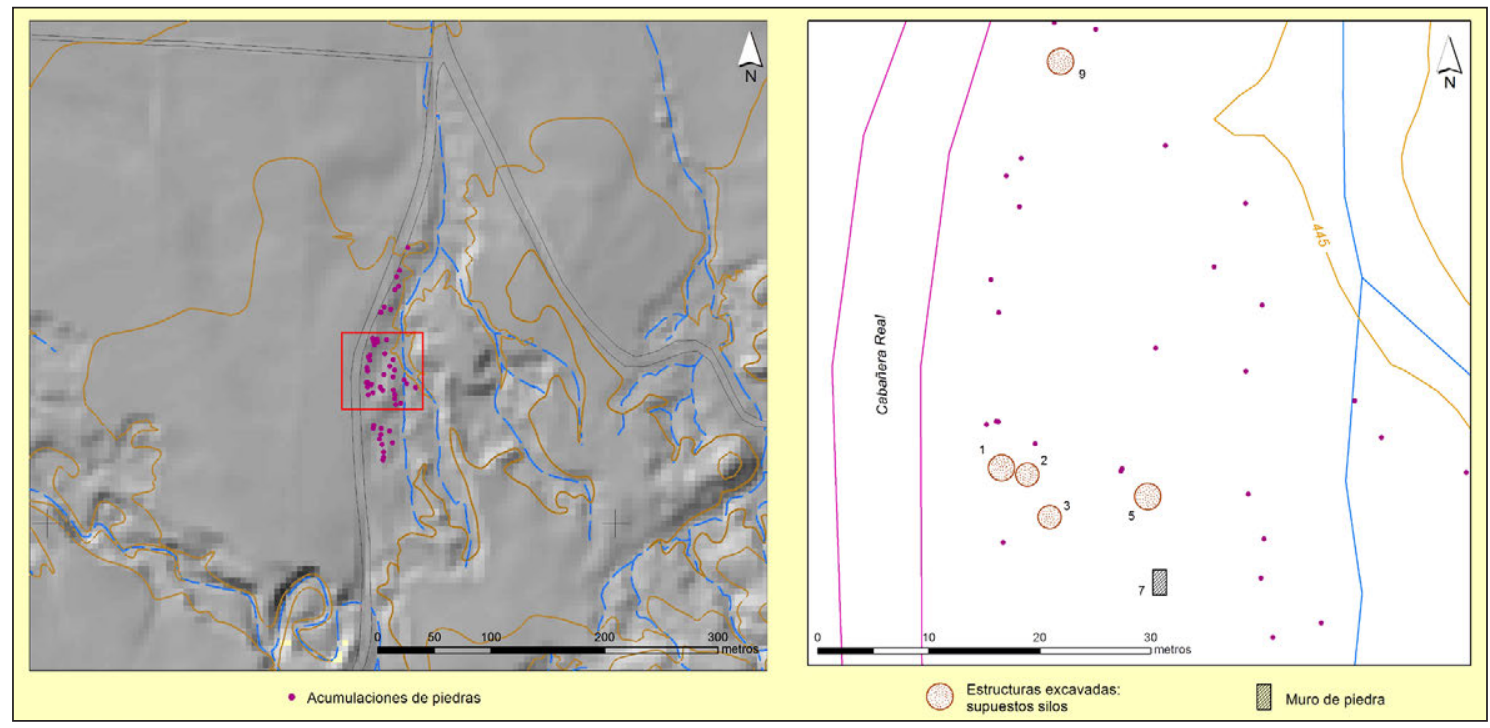

Figura 3. Detalle de la ubicación sobre Modelo Digital de Terreno (MDT05 LIDAR, IGN) y sector central del yacimiento con la distribución de las estructuras/acumulaciones de piedras en las que se intervino en 2014.

con elevado potencial erosivo. Para acometer estas cuestiones procedemos al análisis y evaluación del yacimiento, presentando las estructuras, cronología y los restos materiales, una comparativa a nivel peninsular que sirve para identificar la coyuntura económicosocial en la que se desarrollan estas comunidades y su contextualización local, a través de una visión del poblamiento en la Hoya de Huesca.

\section{EL YACIMIENTO DE LOS PEDREGALES}

Está situado junto al río Sotón ${ }^{9}$, uno de los pequeños cauces subsidiarios del río Gállego que drenan el sector occidental de la Hoya de Huesca, franja de terreno caracterizada por tierras llanas muy productivas, de vocación cerealista, que se extienden al Este del propio río Gállego, entre la sierra de Loarre al norte y el actual embalse de la Sotonera (Fig. 1). Junto a él pasa la llamada Cabañera Real, tradicional vía pecuaria que, con trayectoria N-S, conecta el centro del valle del Ebro con las sierras exteriores y el Pirineo.

El yacimiento se extiende sobre un antiguo cono de deyección desarrollado a los pies de la plataforma estructural miocena denominada Saso Plano, hasta el río Sotón, configurando una superficie llana, con suave pendiente hacia el río. Esta superficie ha experimentado diferentes transformaciones, configurándose en su forma definitiva a partir de la acumulación de un paquete de sedimentos finos de potencia variable, 30-

${ }^{9}$ Coordenadas UTM 6986904669906 (ETRS89, zona 30 N)
$40 \mathrm{~cm}$ en el entorno del yacimiento, que es la base del suelo agrícola actual y que incorpora materiales arqueológicos medievales, modernos y, tal vez romanos, de procedencia incierta. Actualmente está muy afectada por la erosión, favorecida por un barranco con trayectoria S-N y una densa red de incisiones laterales en forma de cárcavas, donde también son evidentes las alteraciones antrópicas relacionadas con remociones de tierras.

Los restos arqueológicos se concentran en la margen izquierda del referido barranco, un sector de badlands de unas 2 ha, siendo perceptibles tanto en la superficie denudada como en los cortes dejados por incisiones y pequeñas cárcavas (Fig. 2). No se descarta que el yacimiento se extienda por los campos vecinos al Oeste de la Cabañera Real, camino que limita la zona erosionada y que está actuando de barrera ralentizando las incisiones remontantes, circunstancia que ya debió obligar a modificar ligeramente su trazado.

Se trata de un conjunto de más de cincuenta acumulaciones de piedras calizas con formas de aspecto tumular y poco más de $1 \mathrm{~m}$ de diámetro, en ocasiones prácticamente cónicas, distribuidas sin orden aparente en una estrecha franja entre el camino $(\mathrm{O})$ y el barranco (E) (Fig. 3). La intensa erosión está desmantelando esas acumulaciones y los depósitos subyacentes que han quedado expuestos. Además hay que anotar la presencia de algún muro de mampostería y también son visibles varias estructuras circulares excavadas en el sustrato limo-arcilloso rellenas por un tipo de sedimento ligeramente grisáceo. Por todo el yacimiento hay material cerámico de cronología 


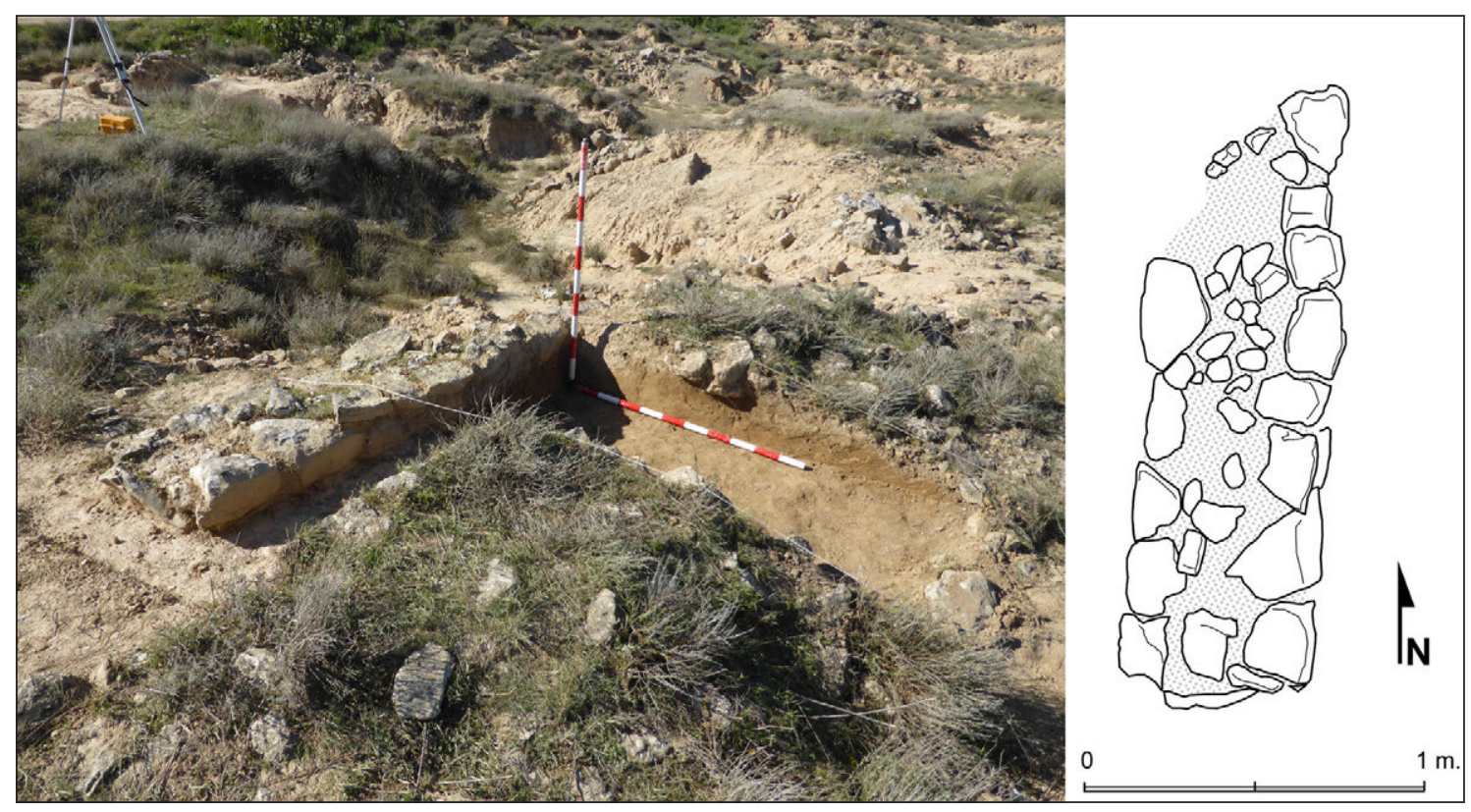

Figura 4. Estructura 7. Tramo de un muro con doble paramento. Vista lateral y planimetría.

romana pero, sobre todo, medieval y moderna. Parte de ese material no proviene de las estructuras, sino que está incorporado en la capa superior que configura el suelo actual y está siendo exhumado por la erosión, propiciando la mezcla de los diferentes grupos cerámicos en superficie. También se encuentran abundantes huesos de animales, algunos estratificados entre las acumulaciones pétreas, así como restos relacionados con el vertido de escombros y basuras recientes.

\section{ESTRUCTURAS}

Ante la enorme transformación y el complejo palimpsesto de restos que confluyen en este lugar, uno de los principales retos ha sido identificar el tipo de estructuras que integran el yacimiento, de manera que sea factible explicar su función principal y los procesos que han incidido en su formación y evolución. En este sentido el estudio geoarqueológico realizado nos ha permitido verificar algunas cuestiones sobre la naturaleza del yacimiento y las, en cierto modo, enigmáticas acumulaciones pétreas ${ }^{10}$.

${ }^{10}$ En la primavera de 2014 procedimos a prospectar de forma detallada el lugar, registrando la posición de todas las estructuras visibles y de aquellos conjuntos de materiales relevantes, óseos o cerámicos, que parecían encontrarse in situ. Paralelamente se tomaron datos para la realización de la topografía general y perfiles transversales con objeto de evaluar y relacionar las distintas superficies reconocidas. A finales de marzo y principios de abril del mismo año, se llevó a cabo una
Los restos más claros corresponden al tramo de unos $2 \mathrm{~m}$ de un muro conservado en superficie (estructura 7, Fig. 4). Es una construcción relativamente robusta, de mampostería de piedra caliza levantada mediante doble hilada, con bloques algo más gruesos en los paramentos exteriores y relleno interior de cantos en matriz arcillosa. Hacia el lado Este se identifican los restos del derrumbe y, por debajo del mismo, se recuperaron varias paredes de cerámica a torno, oxidante y superficie acanalada (Fig. 12, 136). Cabe pensar que esta estructura no estaría aislada, sino que formaría un conjunto constructivo cuya naturaleza no es posible determinar, pero que en cierto modo explicaría los numerosos cantos y bloques dispersos por el yacimiento.

En cualquier caso, la mayor parte de las acumulaciones de piedras están asociadas a estructuras negativas excavadas en el sustrato. Esas unidades, tanto en las que hemos intervenido como en otras observadas en superficie, describen formas curvas (circulares o arcos de círculo) en planta, con dimensiones de poco más de $1 \mathrm{~m}$ de diámetro (Fig. 5). La única que se ha excavado íntegramente define una forma circular ligeramente oblonga (estructura 2, Fig. 6). Además las secciones de estas unidades, en los casos comprobados (estructuras 1, 2 y 3), denotan paredes

breve excavación arqueológica bajo la dirección de Fernando Pérez Lambán, José Luis Peña y Jesús V. Picazo. La actuación se centró en varias acumulaciones de piedras (estructuras 1, 2, 3,5 y 9) y un muro conservado en superficie (estructura 7 ). 
verticales e incluso cóncavas, con trayectorias que apuntan formas "abovedadas". Los rellenos incorporan elementos de origen antrópico, concretamente algo de cerámica, restos de fauna, carboncillos y/o cenizas, que recuerdan contextos tipo basurero, junto con depósitos limo-arcillosos y masas de piedras. Todas estas características se ajustan bien a los criterios que ofrecen diversos especialistas para la discriminación de silos, es decir, pozos excavados en el suelo destinados, fundamentalmente, al almacenaje de grano, respecto a otras estructuras (cfr. Vigil-Escalera 2013a: 128-129).

En lo que hemos podido observar, no se conserva ninguna sección íntegra de esos silos en la que se aprecie su forma, más allá de comprobar que los fondos son planos y que se apuntan perfiles cerrados de boca estrecha. Tampoco tenemos referencias directas para determinar su altura ${ }^{11}$. De hecho, la superficie en la que fueron excavados ha desaparecido casi por completo, aunque como hipótesis podemos relacionarla con la que sirve de base al muro documentado (estructura 7), actualmente reducida a un pequeño tramo horizontal aislado entre cárcavas. Asumiendo esta posibilidad, la profundidad de los silos en los que se ha intervenido $(1,2$ y 3$)$, rondaría los 170,150 y $140 \mathrm{~cm}$, medidas proporcionales a su diámetro (150 y $130 \mathrm{~cm}$ de las estructuras 1 y 2), lo que apunta a capacidades en torno a 25-30 hl, habituales en este tipo de depósitos.

La mayoría de los silos se excavaron en un sustrato formado por arcillas rojizas y depósitos limoarcillosos. Constituyen litologías blandas, fáciles de trabajar y relativamente impermeables, bastante adecuadas para la instalación de estos dispositivos, pero también se erosionan con facilidad y rapide $z^{12}$, lo que justifica que en muchos sectores hayan desaparecido y, con ello, los silos que podían contener. De hecho, en numerosos casos solo se aprecian indicios residuales de esas estructuras (fondos arrasados, cúmulos de piedras dispersas, etc.).

\footnotetext{
${ }^{11}$ Respecto a esta cuestión, Vigil-Escalera (2013a: 128) señala que "el estado de conservación de la cota original de la superficie" es un aspecto clave y poco valorado en los estudios de yacimientos con silos altomedievales. Apunta dos causas principales para la destrucción de esta superficie y de la parte superior de los silos: por un lado las labores agrícolas y por otro las inadecuadas pautas de seguimiento durante los movimientos de tierra de las obras de construcción (Vigil-Escalera 2013a: 142-143). Habría que añadir una tercera causa, que son los propios procesos geomorfológicos, especialmente incidentes en yacimientos ubicados en ambientes semiáridos u otros contextos proclives a la erosión.

${ }^{12}$ A ello contribuye el hecho de que se trata de arcillas con altísimo contenido en sales, lo que aumenta su solubilidad y por tanto el piping. El sodio es un ion dispersante de las partículas, con un SAR por encima de 12 se considera peligroso, pero en el material parental de Pedregales llega a 76,5 (Badía et alii 2009: 86-88)
}

Por otra parte, los silos, una vez terminan su vida útil como contenedores, pasan a ser receptores y acumuladores de materiales diversos, según sea su proceso de abandono, amortización o reutilización. Los rellenos de las estructuras negativas y las formas aparentemente caprichosas, con aspecto tumular que actualmente presentan, son el resultado de intervenciones antrópicas y procesos naturales, que han generado un patrón estratigráfico relativamente regular y repetido en la mayoría de las estructuras. En cuanto a los rellenos, de abajo a arriba podemos encontrar:

1. En la base de los silos y, en ocasiones, de forma interestratificada, se encuentran depósitos laminares de arenas muy finas con disposición horizontal entre las que se identifica algún carboncillo. Parecen el resultado de la infiltración de agua y lavado de paredes, proceso que podría darse en silos abandonados y total o parcialmente vacíos.

2. Algunos silos presentan capas cenicientas con cerámicas y huesos (estructura 3, Fig. 7). En otros casos estos mismos restos se encuentran algo más dispersos. Corresponden a depósitos de basuras que tienden a acumularse en el fondo de esas estructuras tras su abandono. También se ha identificado la porción delantera de un bóvido en conexión anatómica entre los bloques superiores de una las acumulaciones (estructura 9, Fig. 8) ${ }^{13}$. Parece responder al uso típico del silo una vez abandonado como "contenedor último de productos en descomposición”, por lo que no es raro encontrar partes anatómicas de reses, animales completos o, incluso, cadáveres humanos (Vigil-Escalera 2013a: 132; Roig 2013). En el caso que nos ocupa, es de suponer que este uso secundario obedece a una intención profiláctica, puramente práctica, como viene siendo habitual en muchas sociedades tradicionales más allá de otras posibles interpretaciones (cfr. Morris 2011).

3. Es común en todas las estructuras documentadas un potente relleno más o menos homogéneo de tipo arcilloso, compacto, con inclusiones de bloques y cantos calcáreos, abundantes carboncillos y algún resto óseo y cerámico. Parece tratarse de un relleno antrópico, cuyo objeto es el sellado de los silos una vez amortizados (cfr. Vigil-Escacena 2013: 131). Este relleno suele

\footnotetext{
${ }^{13}$ Por la superficie del yacimiento se observan otros restos óseos en conexión, pero no se puede asegurar su relación con las estructuras negativas puesto que la presencia de basura actual y escombros nos indica la utilización de este espacio hasta fechas muy recientes como vertedero.
} 


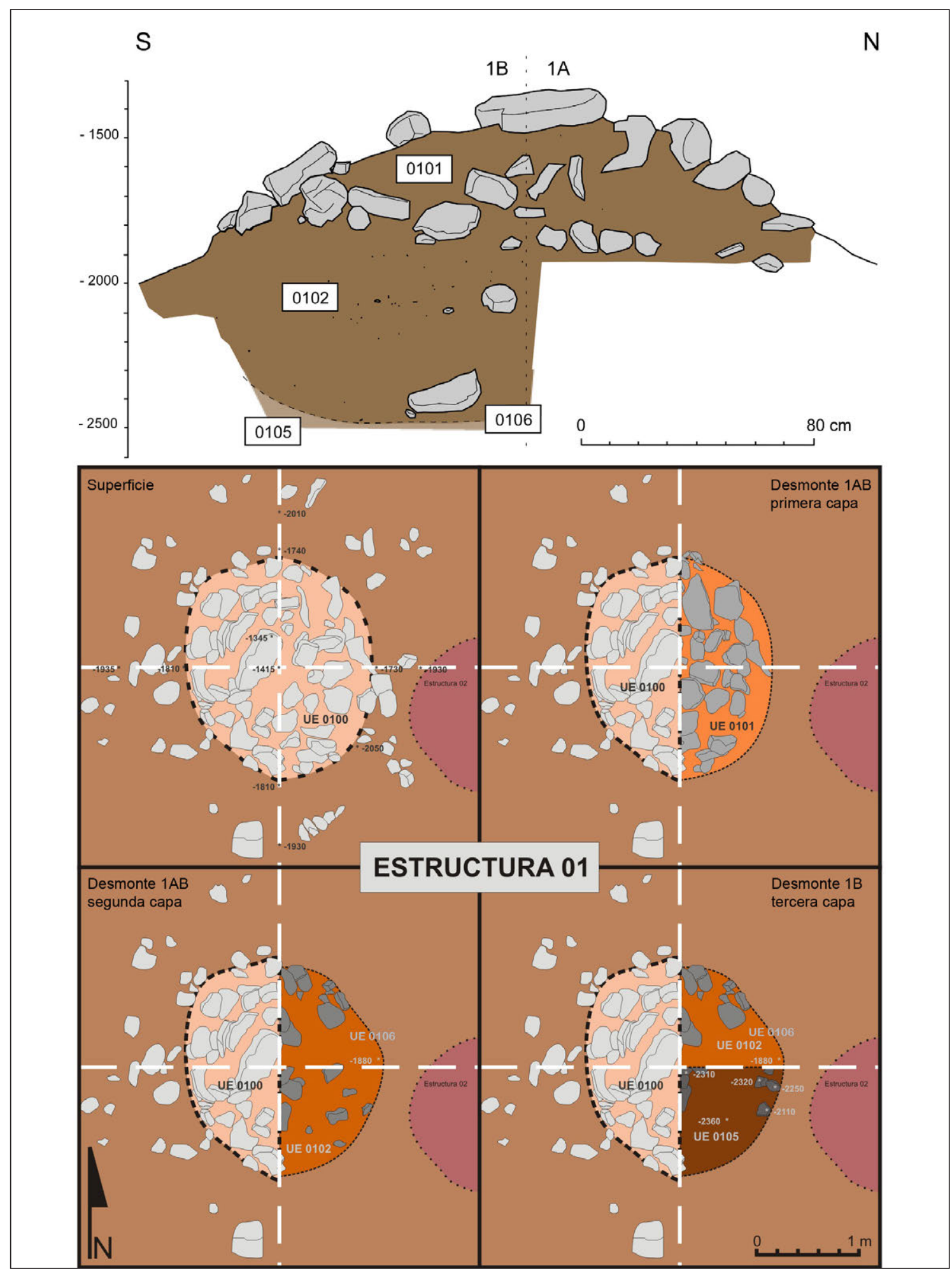

Figura 5. Estructura 1. Vista cenital de la acumulación de piedras antes de la intervención. Corte estratigráfico N-S. Planimetría superficial y de los sectores excavados. 


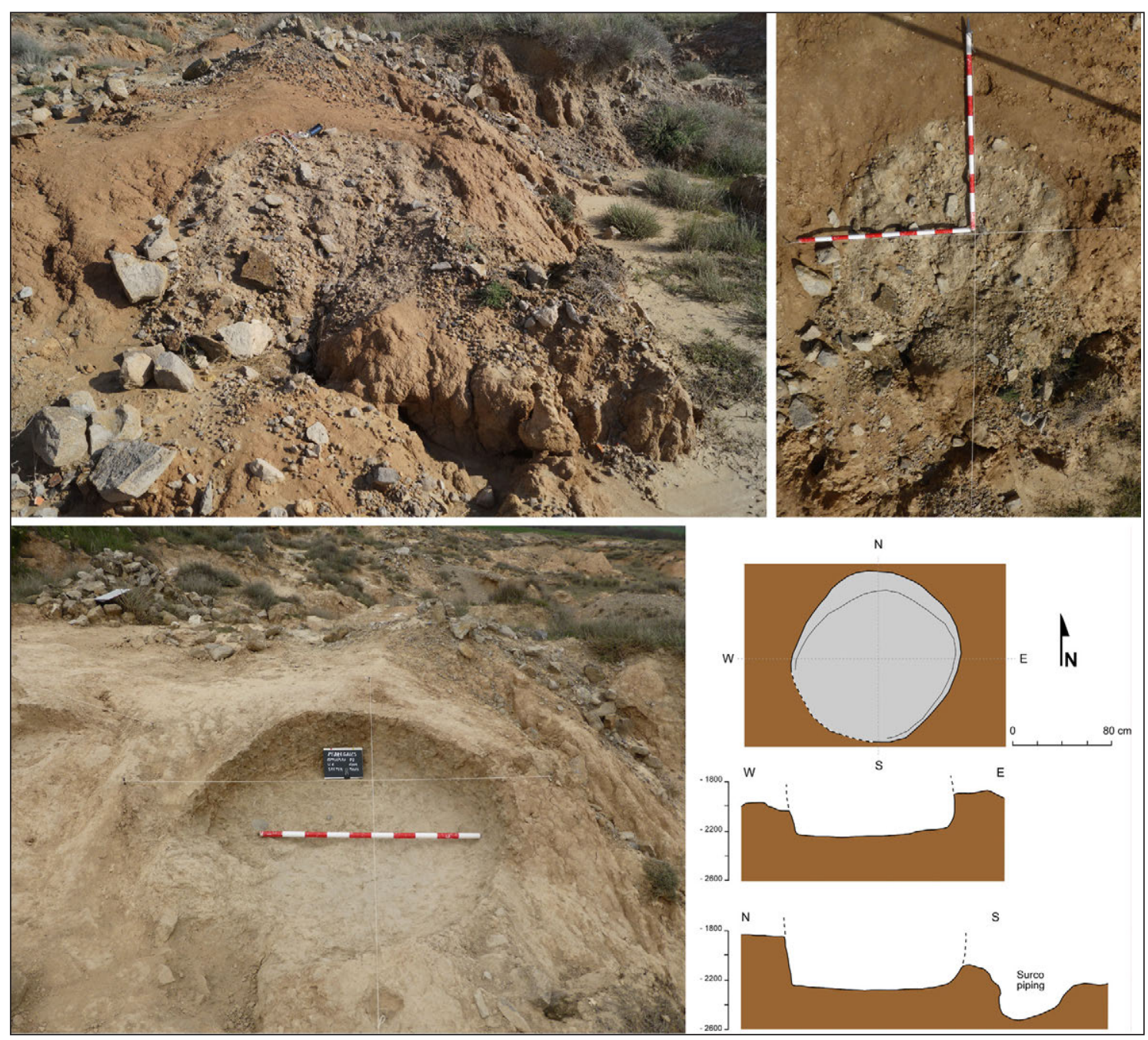

Figura 6. Estructura 2. Estado al inicio y final de la excavación. Planimetría y perfiles del silo.

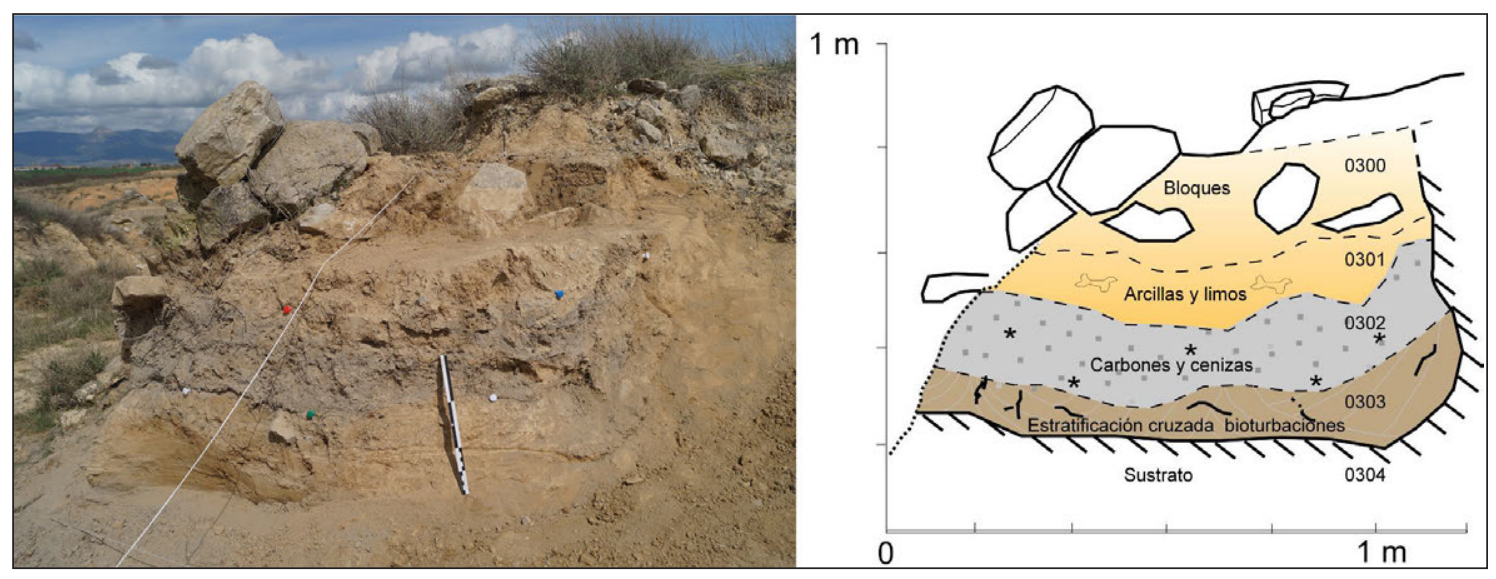

Figura 7. Estructura 3. Vista lateral en el inicio de los trabajos y perfil estratigráfico. 


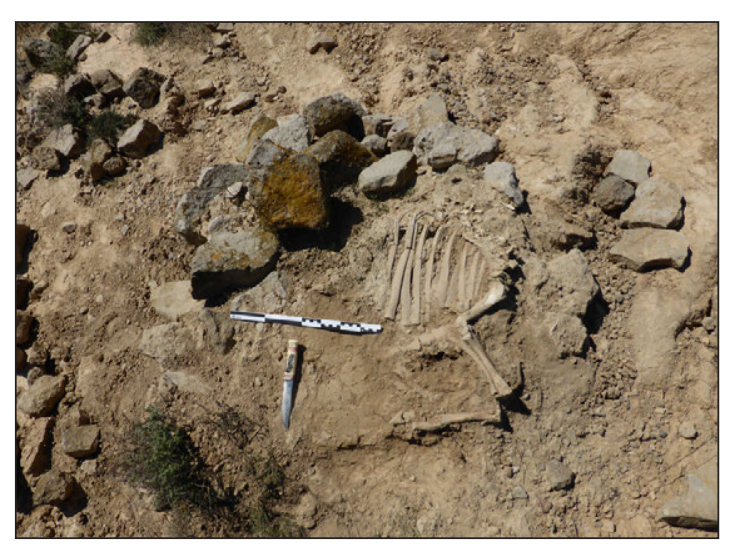

Figura 8. Estructura 9. Restos esqueléticos de B. Taurus tras la primera limpieza de bloques.

ser intencional y oportunista, aprovechando el material que se tiene a mano. Por tanto es lógico pensar que se aprovecharan las arcillas y limos del sustrato (componente principal), materiales de construcción, las piedras que cubrían los propios silos, basuras de los alrededores, etc.

4. Una mayoría de los supuestos silos presentan acumulaciones importantes de piedras calizas en apariencia ordenadas que dan lugar a formas circulares. Sus orientaciones también son relativamente regulares. En algunos casos se disponen de forma completamente vertical (estructuras 1, 4 y 8) y suelen estar pegadas al límite del pozo. En otras se encuentran inclinadas convergiendo hacia un punto más o menos central (estructura 9, así como algunos bloques de las estructuras 1 y 3). Semejante disposición se ajusta bastante bien al relleno, natural o intencionado, de una depresión circular parcialmente colmatada como pudieron ser los silos.
Teniendo en cuenta esta secuencia acumulativa, el hecho de que las concentraciones de piedras aparezcan en positivo con formas aproximadamente troncocónicas y con escasa matriz puede explicarse por erosión diferencial del sustrato arcilloso en el que está excavado el silo, mucho más blando que los rellenos, y el subsiguiente lavado del material fino existente entre los bloques calizos. Además, conforme se produce la erosión diferencial y la exposición de las acumulaciones de piedras, estas tienden a desmoronarse lateralmente con caída de bloques por los lados de las formas resultantes, más o menos troncocónicas.

Entre esas piedras suele aparecer una losa plana, más grande $(50-60 \mathrm{~cm}$.), que funcionaría como tapadera para la boca del silo. Losas con esas características se encuentran por todo el yacimiento, tanto aisladas como entre las acumulaciones de bloques (Fig. 9), mostrando una disposición que, una vez erosionado el contenedor, recuerda a la documentada en otros silos medievales (cfr. Alonso et alii 2002: 255).

Completa el panorama descrito la identificación de alguna estructura circular prácticamente arrasada, afectada por procesos activos de piping, pero que conserva la base con indicios de rubefacción perimetral y, de nuevo, una losa plana en el centro (Fig. 10). Esta morfología y la incidencia de fuego es uno de los rasgos señalados por Vigil-Escalera (2013a: 129-131) que ayudan a identificar los silos, cuya función sería consolidar las paredes o sanearlo después de su uso.

Lo habitual es que estos silos se agrupen formando campos sin un orden determinado, lo que convendría con la amplitud y dispersión de los restos documentados. El patrón lineal que parece identificarse en la distribución (Fig. 3), no es sino el resultado del modelado generado por las incisiones en forma de surcos profundos y barranqueras con trayectorias casi paralelas en la dirección del barranco principal, Sur-Norte.

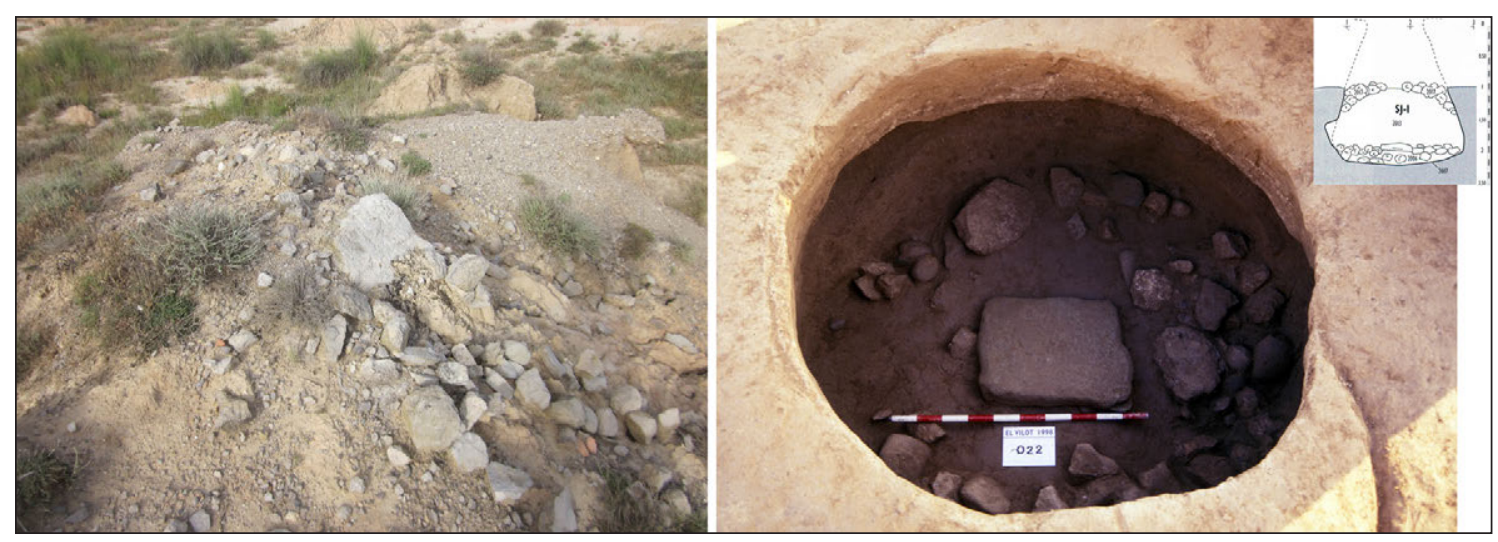

Figura 9. Acumulación de piedras con losa en el centro. A la derecha silo 1 del Vilot de Montagut, de cronología islámica (Alonso et alii, 2002: 255), en cuyo fondo se observa una losa de cierre y bloques. 


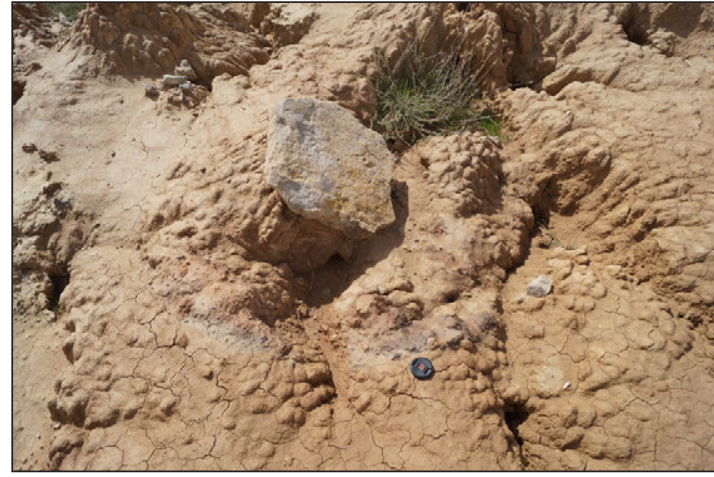

Figura 10. Fondo de un posible silo con losa en el centro y signos de rubefacción perimetral.

Estos campos de silos pueden estar asociados a algún establecimiento de tipo rural. Vigil-Escalera (2013a: 131 y ss) anota que los silos de las inmediaciones de las viviendas tienden a rellenarse de forma intencional y rápida, incorporando residuos de las actividades cotidianas, mientras que los de la periferia presentan colmataciones naturales. Desde esta perspectiva, los silos excavados en Los Pedregales estarían asociados a viviendas. Sin embargo, no se ha llegado a identificar ningún resto constructivo significativo de ese posible asentamiento, pues la posición del único muro que se ha documentado (estructura 7, Fig. 4) sobre una superficie residual no permite conectarlo directamente con los silos.

En definitiva, más allá de la existencia de construcciones cuya entidad, naturaleza y cronología resultan difusas, el yacimiento de Los Pedregales, responde a un extenso campo de silos en el que es posible identificar más de 50 unidades. Actualmente está parcialmente arrasado por la erosión y sólo es reconocible por restos residuales y, sobre todo, por los rellenos de esas estructuras negativas que quedan en resalte, habida cuenta que resultan más consistentes que el sustrato en el que fueron excavados silos.

\section{Dataciones absolutas}

Se enviaron dos muestras de carbones recuperados en las estructuras 1 y 2 al laboratorio de la Universidad de Gröningen para su datación por AMS. Los resultados obtenidos se han calibrado con el programa CalPal online para la obtención de valores medios y el programa Calib v.7 sobre la curva INTCAL13 para la estimación de los intervalos de máxima probabilidad.

Los Pedregales 1: GrA-60640 $1520 \pm 30$ bp 522 \pm 53 calAD
One Sigma Ranges: [start:end] relative area Two Sigma Ranges: [start:end] relative area

[cal AD 437: cal AD 445] 0.062129 [cal AD 428: cal AD 496] 0.309115

[cal AD 473: cal AD 486] 0.11112 [cal AD 506: cal AD 522] 0.033774

[cal AD 535: cal AD 596] 0.826752 [cal AD 526: cal AD 609] 0.657111

Estructura 1, unidad 0102. Carbones de P. halepensis, B. sempervivens, $Q$. ilex coccifera y fam. Leguminosae.

Los Pedregales 2: GrA-60642 $1300 \pm 30$ bp 712 \pm 39 calAD

One Sigma Ranges: [start:end] relative area Two Sigma Ranges: [start:end] relative area

[cal AD 669: cal AD 695] 0.512309 [cal AD 660: cal AD 730] 0.676931

[cal AD 700: cal AD 710] 0.144018 [cal AD 736: cal AD 769] 0.323069

[cal AD 745: cal AD 764] 0.343673

Estructura 2, unidad 0204. Ramita de Laurus nobilis recuperada junto con otros carbones en la base de la estructura.

Los resultados de los análisis datan el relleno de los silos en época visigoda, concretamente en torno a la segunda mitad del siglo vi el primero de ellos y segunda mitad del siglo vII, alcanzando incluso los inicios del siglo viII, para el segundo. Se aprecia, por tanto, una diferencia de unos 150 años entre las dos dataciones, lo que parece indicar que las dos estructuras no se rellenaron/amortizaron al mismo tiempo. Además, hay que tener en cuenta que ambas fechas sitúan los momentos de abandono y colmatación, por lo que su excavación y uso primario tuvo que ser anterior, aunque difícil de determinar debido a la posible utilización plurigeneracional de los silos de grano (Vigil-Escalera 2013a: 141).

En cualquier caso y aunque solo disponemos de dos dataciones para poder precisar la cronología de un conjunto tan extenso, nos informan de dos momentos de uso y plantean la posibilidad, bastante razonable por otro lado, de que las numerosas estructuras negativas que constituyen el yacimiento sean el resultado de un proceso acumulativo a lo largo del cual se van utilizando y amortizando.

\section{Materiales}

Como se viene comentando, en el yacimiento se superponen materiales heterogéneos, tanto en su naturaleza, cronología, como en los contextos de pro- 


\begin{tabular}{|c|c|c|c|c|c|c|c|c|c|c|c|c|c|c|c|}
\hline & & \multicolumn{2}{|c|}{$\begin{array}{l}\text { Est. 01 } \\
\text { Silo }\end{array}$} & \multicolumn{2}{|c|}{$\begin{array}{l}\text { Est. 02 } \\
\text { Silo }\end{array}$} & \multicolumn{2}{|c|}{$\begin{array}{c}\text { Est. 03 } \\
\text { Silo }\end{array}$} & \multicolumn{2}{|c|}{$\begin{array}{l}\text { Est. 05 } \\
\text { Silo }\end{array}$} & \multicolumn{2}{|c|}{$\begin{array}{c}\text { Est. 07 } \\
\text { Silo }\end{array}$} & \multicolumn{2}{|c|}{$\begin{array}{c}\text { Est. 09 } \\
\text { Silo }\end{array}$} & \multirow{2}{*}{ 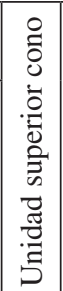 } & \multirow{2}{*}{ 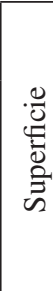 } \\
\hline & & 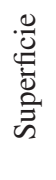 & 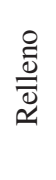 & 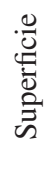 & 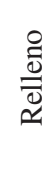 & 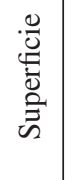 & $\begin{array}{l}\stackrel{\Xi}{\Xi} \\
\frac{0}{\bar{\Xi}}\end{array}$ & 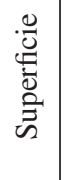 & 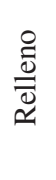 & 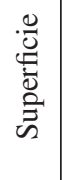 & 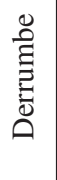 & 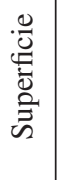 & $\frac{\stackrel{\Xi}{0}}{\stackrel{\overrightarrow{0}}{\simeq}}$ & & \\
\hline \multirow{5}{*}{ Cerámicas } & Romana s. I a.C. & & & & & & & & & & & & & & \\
\hline & Gris altomedieval s. VI-IX & & & & & & & & & & & & & & \\
\hline & Torno oxidante s. XI-XX & & & & & & & & & & & & & & \\
\hline & Molde vidriada s. XIII-XIV & & & & & & & & & & & & & & \\
\hline & Torno vidriada s. XIII-XX & & & & & & & & & & & & & & \\
\hline \multirow{2}{*}{ Monedas } & Felús s. VIII & & & & & & & & & & & & & & \\
\hline & Dinero s. XVII & & & & & & & & & & & & & & \\
\hline \multirow{9}{*}{ Fauna } & Indeterminado & & & & & & & & & & & & & & \\
\hline & Ovicáprido & & & & & & & & & & & & & & \\
\hline & Bóvido & & & & & & & & & & & & & & \\
\hline & Conejo & & & & & & & & & & & & & & \\
\hline & Zorro & & & & & & & & & & & & & & \\
\hline & Ave & & & & & & & & & & & & & & \\
\hline & Galápago & & & & & & & & & & & & & & \\
\hline & Marcas de carnicería & & & & & & & & & & & & & & \\
\hline & Marcas de dientes & & & & & & & & & & & & & & \\
\hline \multirow{3}{*}{ Otros } & Basura moderna & & & & & & & & & & & & & & \\
\hline & Metales/Minerales & & 1 & 2 & & & & 3 & & & & & & & 4 \\
\hline & & \multicolumn{14}{|c|}{ 1. Escoria de $\mathrm{Fe} 2 . \mathrm{Fe} 3 . \mathrm{Fe}$, Riolita/malaquita 4. Varilla bronce, otros... } \\
\hline
\end{tabular}

Figura 11. Cuadro resumen con los materiales y contextos en los que aparecen.

cedencia, formando una especie de palimpsesto que es necesario descomponer y limpiar de "ruido" para concretar el significado de cada conjunto.

En el cuadro adjunto (Fig. 11) presentamos un resumen de los tipos de materiales y los contextos en los que aparecen. Hay que precisar que, independientemente de los recuperados en superficie, los que aparecen estratificados se vinculan a dos contextos bien definidos: los rellenos de los silos, que incorporan casi exclusivamente cerámicas grises altomedievales así como huesos de animales consumidos, y la capa superior que conforma la superficie actual y que incluye cerámicas a torno oxidantes medievales y/o modernas.

\section{CERÁmicAs}

Por todo el yacimiento encontramos numerosos fragmentos componiendo un conjunto integrado por cuatro grupos cerámicos: producciones romanas, cerámicas grises toscas altomedievales, cerámicas más o menos finas de cocción oxidante y cerámicas vidriadas. Esta composición podría explicarse por un uso prolongado del lugar, pero hay que tener presente la incorporación de materiales derivados de entornos próximos, su integración en la capa superior del suelo y, finalmente, su exposición en superficie tras la erosión de esa capa. Tal vez por ello, esa heterogeneidad de la cerámica superficial no concuerda con el resultado de las excavaciones, pues a partir de ellas se documenta un conjunto homogéneo, integrado casi exclusivamente por cerámicas grises, toscas, elaboradas a mano y/o a "torno lento".

\section{Cerámicas de época romana}

En las diferentes prospecciones realizadas se constata el hallazgo de cerámicas romanas de época republicana, entre ellas dos fragmentos de cerámica de barniz negro tipo $B$, algún fragmento de cerámica fina oxidante, una pared de ánfora republicana tipo 


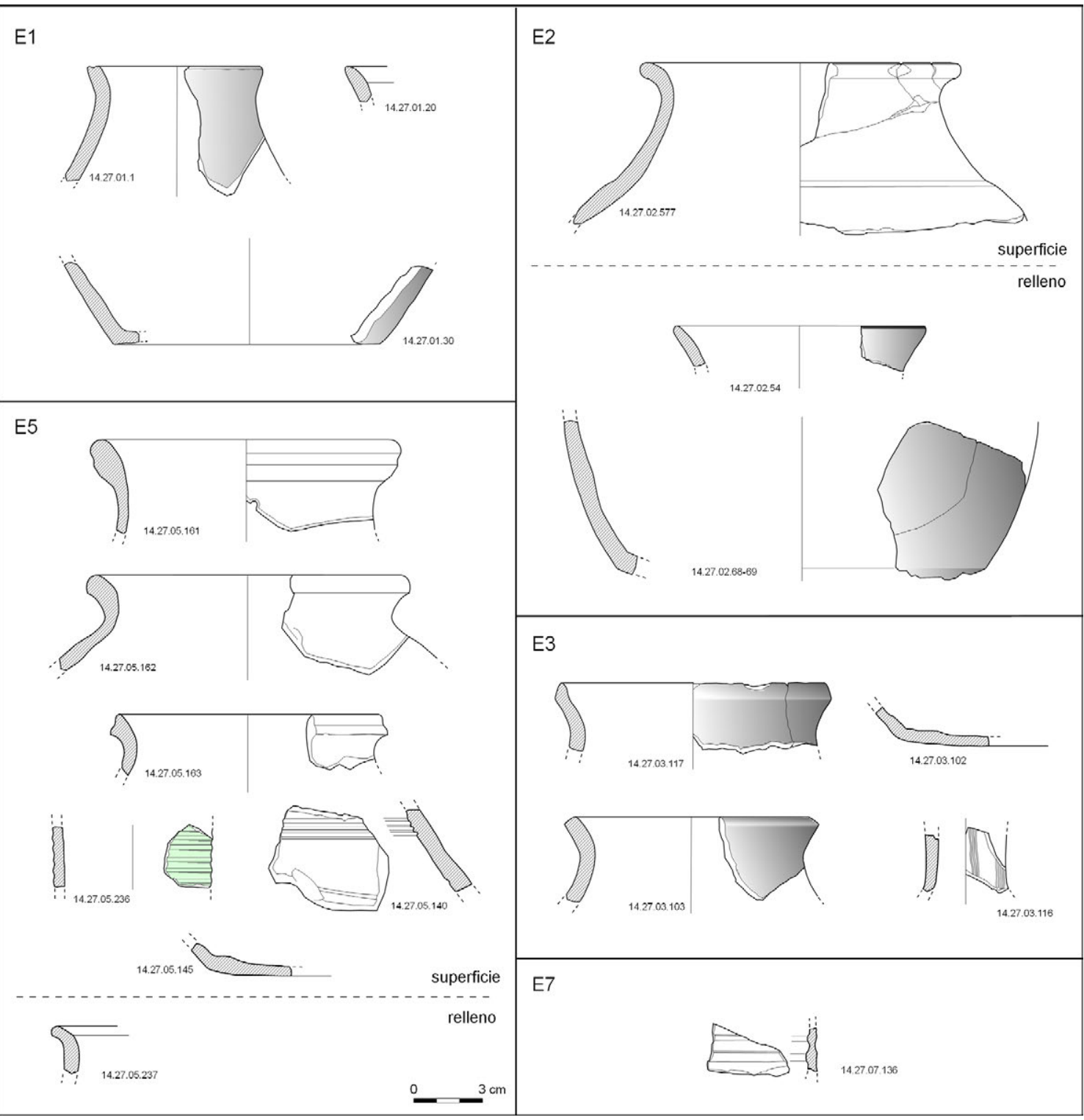

Figura 12. Conjunto de cerámicas recuperadas en los silos (E1, E2, E3, E5) y otras estructuras (E7), tanto en la superficie de los mismos como en sus rellenos.

Dressel, localizada entre los materiales superficiales recuperados en la estructura 5, y un fragmento de pared oxidante con engobe marrón-rojizo.

No contamos con datos estratigráficos ni superficiales que nos permitan estimar una procedencia concreta para estas cerámicas. Sí hay que señalar que algunos fragmentos presentan fracturas y aristas con indicios de rodamiento, mayor que para cualquier otro grupo cerámico, por lo que hay que tener en cuenta la posibilidad de cierto grado de movilización.

\section{Cerámicas grises altomedievales}

Es el grupo cerámico más relevante. Se han recuperado fragmentos de esta clase en los rellenos de los silos 1 (n ${ }^{\text {os }} 1,20$ y 30$), 2$ (n ${ }^{\text {os }} 54$ y 68-69), 3 $\left(\mathrm{n}^{\text {os }} 102,103\right.$ y 117$)$ y 5 (n ${ }^{\text {os }} 145$ y 237$)$, siendo las únicas producciones documentadas en los silos 1, 2 y 5 (Fig. 12). También son muy frecuentes en toda la superficie del yacimiento formando concentraciones que pueden proceder del desmantelamiento 


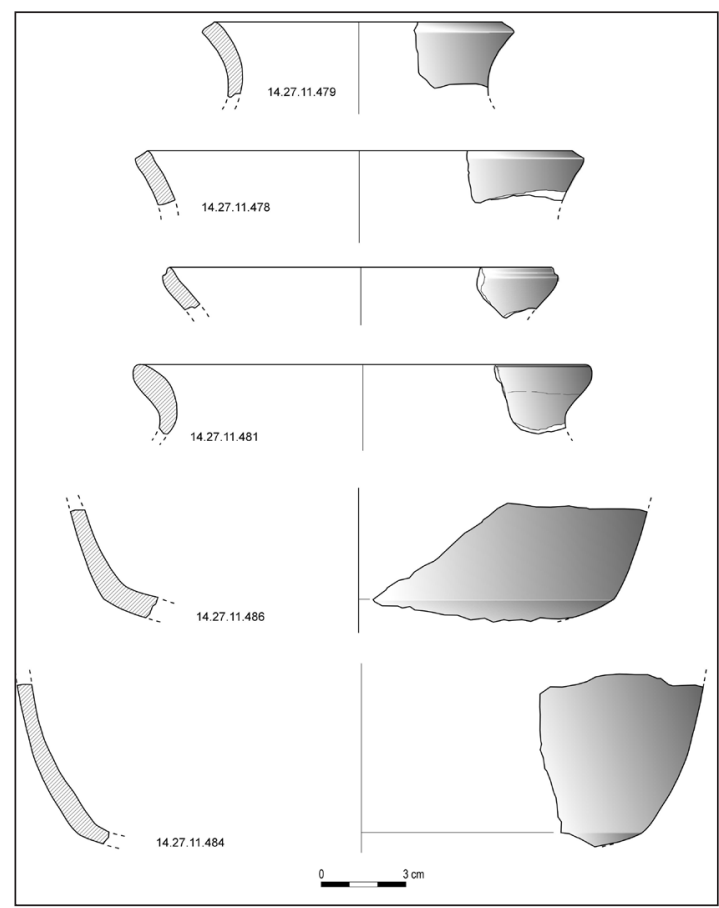

Figura 13. Cerámicas comunes con cocción reductora localizadas en el punto $\mathrm{n}^{\circ} 11$.

de los citados graneros subterráneos (conjunto $\mathrm{n}^{\circ}$ 11, Fig. 13).

Se trata de cerámicas grises, relativamente toscas, elaboradas a partir del uso de pastas con proporciones medias y elevadas de desgrasante de dos tipos diferentes. El primero corresponde a inclusiones angulosas y bastante regulares de cuarzo, mica y, tal vez, feldespato, por lo general de tamaño medio-fino, que parecen proceder de la trituración e incorporación intencional en la arcilla de algún tipo de granito. Más escasas son las pastas con granos redondeados de cuarzo o cuarcita, combinados con algún punto micáceo y otros componentes más difíciles de identificar de visu. Posiblemente, estaban incorporadas de forma natural en los depósitos aluviales empleados como materia prima para la elaboración de las cerámicas. El modelado de las piezas se llevó a cabo mayoritariamente a mano, aunque en algunos fragmentos se pueden observar líneas formadas por el uso de tornetas o tornos bajos de giro lento, lo que explica las irregularidades en el espesor de algunas paredes, relativamente gruesas comparadas con producciones posteriores. Los tratamientos de superficie, cuando aparecen, suelen ser muy sumarios, por lo general leves alisados, que confieren a la pieza un aspecto tosco y descuidado. La coloración gris oscura de los fragmentos, tanto al exterior, como en corte, es resultado de cocciones reductoras, probablemente en hornos de cámara única o doble excavados en el terreno ${ }^{14}$.

Las formas identificadas son, en general, bastante simples: fondos planos o levemente convexos, cuerpos con perfiles sinuosos para una eficiente distribución del calor, cuellos poco marcados y bordes abiertos con labios planos, redondeados o apuntados. En algunos casos presentan un bisel interno o una ligera inflexión junto al borde destinada a asentar la tapadera. En su mayor parte deben corresponder a marmitas, ollas $\mathrm{y}$, en general, formas destinadas a la transformación de alimentos en caliente, tal como se deduce de las marcas de combustión, a modo de fogonazos, en la superficie exterior. Este tipo de ollas con perfiles en $\mathrm{S}$ presentan una amplia dispersión por toda la península a pesar de la existencia de variaciones regionales. Los modelos que identificamos en Los Pedregales no difieren de las formas básicas documentadas en el valle del Ebro y en buena parte del norte, oeste y centro peninsular (cfr. Alba y Gutiérrez 2008: 586; Vigil-Escalera 1999). Tal vez el rasgo más peculiar sea la presencia de una carena baja en algunas piezas (Fig. 12, 68-69 y fig. 13, 484 y 486), que parece configurar un fondo convexo en vez de plano que recuerda la morfología inferior de algunas marmitas.

La función concreta de estas formas es difícil de determinar. Se ha sugerido que, a diferencia de cazuelas y ollas abiertas, destinadas principalmente a obtener con cierta rapidez guisos relativamente secos, las pequeñas ollas de boca estrecha servían sobre todo para llevar a cabo cocciones lentas a elevadas temperaturas de preparaciones semilíquidas (sopas, hervidos, estofados, etc.) (Arthur 2007; Vroom 2009).

Estas producciones siguen siendo objeto de atención por el interés y, en cierto modo, ambigüedad cronológica que presentan, habida cuenta de su origen tardorromano y su continuidad en contextos andalusíes (cfr. Alba y Gutiérrez 2008). En el ámbito del NE peninsular los mejores paralelos pueden rastrearse en el conocido yacimiento de El Bovalar (Serós, Lérida), en las riberas del bajo Segre, donde se ha documentado un amplio y poco estandarizado repertorio de principios del siglo vIII, compuesto principalmente por orzas, ollas y sobre todo jarras de mediano y pequeño tamaño con marcas de fuego (Cau et alii 1997). Tam-

\footnotetext{
${ }^{14}$ Coll y García (2010) han documentado la cocción de ollas modeladas a torno lento, datadas en el siglo x, en dos instalaciones del Castellar de Meca (Ayora). Se trata de hornos con doble cámara escalonada que denominan "hornos de ladera". Como su nombre indica aprovechan un desnivel del terreno para excavar el hogar o cámara de combustión en el escalón inferior y la cámara de cocción en el escalón superior, conectando ambas mediante un conducto anterior y otras toberas secundarias dirigidas hacia la parte posterior de la cámara.
} 


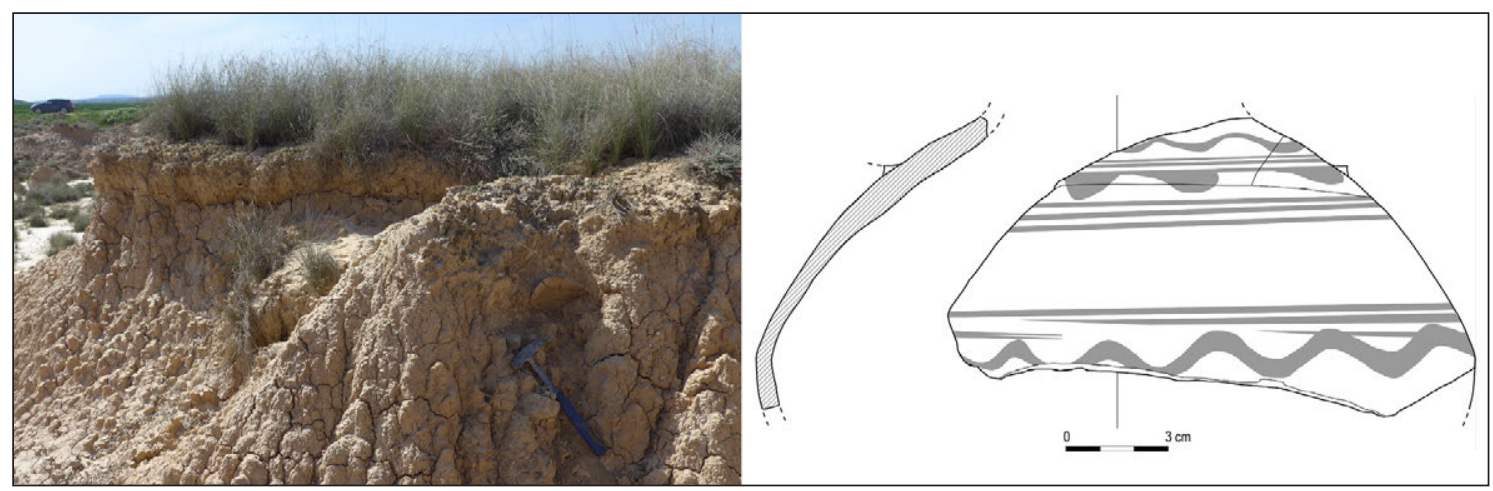

Figura 14. Pequeño cántaro (14.27.580) incorporado en la capa superior del cono.

bién se han identificado en el hallazgo parcialmente inédito del Sisallar (Sobradiel, Zaragoza), junto a los restos de un hogar o una hoguera, interestratificada en un cono de deyección, con fecha $496 \pm 53$ cal AD (Constante et alii 2011: 278), en yacimientos como la Cuesta de la Calera (Ariza, Zaragoza), ocupado en el siglo viI o inicios del viII d. C. (Rodríguez 2014: 333), o la fortaleza del Cerro Calvario (Puebla de Castro, Huesca), datado en época emiral (Asensio y Magallón 2011: 102). Están ausentes, sin embargo, otras formas posteriores del siglo IX, consideradas buenos indicadores del proceso de islamización, en especial las jarritas de ancho cuello tubular y una sola asa, caso de las documentadas en la calle Santiago de Zaragoza (Galve 1988; Hernández y Bienes 2003). Estos apuntes cronológicos ratifican los momentos iniciales de la ocupación del yacimiento a finales del siglo VI y proyectan su continuidad hasta mediados del IX. Pero además aportan una nueva referencia que confirma el origen preislámico de esta clase de cerámica modelada, cuya forma característica y básica, la olla con perfil en S, más allá de las diversas variantes regionales, aparece de forma recurrente en contextos tardoantiguos de tradición visigoda (Alba y Gutiérrez 2008: 586). Parece claro, en todo caso, que la conquista islámica y la integración de este sector del valle del Ebro en los dominios omeyas, deducible de la aparición de feluses acuñados en el siglo VIII (Fig. 16), no supuso ningún tipo de cesura tecnológica a corto plazo. Las tradiciones alfareras, al menos, se mantuvieron con escasas alteraciones durante algunas décadas.

Desde un punto de vista estrictamente tecnológico, estas cerámicas, fabricadas en ambientes domésticos con ayuda de procedimientos muy básicos y poco especializados, resultan plenamente coherentes con la arquitectura de almacenaje representada por los silos. Ambos son productos de la generalizada simplificación de las cadenas operatorias en los procesos de trabajo (Azkárate y Quirós 2001; Arthur 2006: 167; Alba y Gutiérrez 2008: 586), característica de las formas de producción campesinas que siguieron a la desarticulación del entramado económico del sistema de villae a partir del siglo $\mathrm{V}$, basadas en la preeminencia de la producción para el autoconsumo de la unidad doméstica (Wickham 2005, Quirós y Vigil-Escalera 2006). Entendemos que, a pesar de ciertos datos, estas cerámicas modeladas participan de esa estrategia productiva de carácter doméstico (Alba y Gutiérrez 2008: 586), lo que no es contradictorio con la identificación de producciones a mayor escala en hornos medianos y grandes a partir del siglo $\mathrm{x}^{15}$, incluso su difusión/comercialización fuera del ámbito local, probablemente ya en el seno de una estructura económica diferente (Travé y Padilla 2013: 114), aunque permanezca el gusto por un tipo de producto muy asentado en la población ya que cumple sobradamente sus necesidades funcionales.

\section{Cerámicas a torno de cocción oxidante}

Disperso por toda la superficie del yacimiento, se ha recuperado un lote cerámico caracterizado por el modelado sobre tornos rápidos combinado con la cocción en ambientes oxidantes. En general, se trata de fragmentos de ollas y jarras de cuellos acanalados $\mathrm{y}$ decoraciones incisas realizadas a peine o pintadas.

El contexto tecnológico de estas cerámicas resulta claramente distinto - y posterior — al grupo de cerá-

${ }^{15}$ La identificación de los dos hornos de doble cámara en ladera en el Castellar de Meca para la cocción de cerámicas grises torneadas (Coll y García 2010) puede apuntar en esta línea, pero desde luego resulta más significativo de ese posible cambio algunos grandes centros productores de cerámica gris, como los de Cabrera d'Anoia y Casampons, que parecen absorber otros talleres menores y cuya producción pudo abastecer a buena parte de la Cataluña central (Travé y Padilla 2013: 114). 
micas altomedievales, lo que se aviene con el hecho de que, en líneas generales, no compartan los mismos niveles estratigráficos. Sí que es cierto que los silos excavados son pocos, pero llama la atención que en los rellenos solo se haya recuperado un fragmento de cuello de una posible botella o jarra con pasta muy depurada, color ocre claro e incisiones verticales realizadas a peine en la estructura 3 (Fig. 12, 116) que podría vincularse con la Forma E de Gutiérrez (1986: 159). Por ello parece dibujarse un panorama dominado por las cerámicas grises de tradición preislámica, en el que se incorporan otras producciones que suelen considerarse más tardías, no anteriores al siglo IX, pero que bien podrían anticiparse (cfr. Alba y Gutiérrez 2008: 607).

Independientemente, la mayoría de las piezas torneadas de cocción oxidante se han encontrado en superficie o estratificadas en las capas superficiales del yacimiento, sin que puedan vincularse a contextos bien definidos. Entre ellas destacan los fragmentos de un cántaro pintado con bandas y ondas en negro sobre engobe crema, un tipo documentado en niveles islámicos del arrabal meridional de Zaragoza, sobre todo en el siglo XI (Gutiérrez y De Miguel 2010: 439). Estaba integrado en la capa que conforma la superficie actual (Fig. 14), de la que parecen proceder los numerosos fragmentos de esta clase cerámica que se encuentran por toda la zona, especialmente en la superficie de la estructura 5 (Fig. 12).

Caso distinto es el de tres fragmentos pertenecientes probablemente a un mismo vaso con cuerpo globular y superficie ondulada/acanalada, elaborado con pasta ocre-anaranjada de buena calidad (Fig. 12, 136). Fueron recuperados bajo del nivel de derrumbe del único muro documentado en el yacimiento (estructura 7). El valor cronológico de los mismos es limitado, así como las posibilidades de conexión de este contexto con el resto de las estructuras negativas.

\section{Cerámicas vidriadas}

Se han recuperado unos pocos fragmentos dotados de cubierta vidriada. Para su fabricación se emplearon pastas claras de tonos amarillentos bien depuradas y vidriados, más finos en la cara interna, de tonos pálidos, verdes y amarillos. Destaca un fragmento del cuello cilíndrico, localizado en la superficie de la estructura 5, que apunta a una jarra de cronología cristiana. Presenta superficie acanalada y vidriado en tonos verdosos (Fig. 12, 236).

En la misma línea se han identificado tres fragmentos de un jarro, parte del pico vertedor y una banda decorada con eses enlazadas en la unión del cuello y el cuerpo globular (Fig. 22). El interés de este fragmento radica en el procedimiento de fabricación, a molde, que lo vincula con una serie de formas destinadas el servicio de alimentos y bebidas, sobre todo jarras, documentadas en entornos urbanos de la mitad septentrional de la península Ibérica en contextos del siglo XIII y principios del XIV, como Zaragoza, Tudela, Logroño, Vitoria, Pamplona, Burgos, Valladolid, etc. (Ramón 2013). Su aparición en medios rurales es más rara, pero su presencia ha sido registrada en las Cinco Villas, concretamente en Corral de Calvo (Luesia, Zaragoza), donde se recuperó un amplio conjunto de cerámicas similares (Paz et alii 1992).

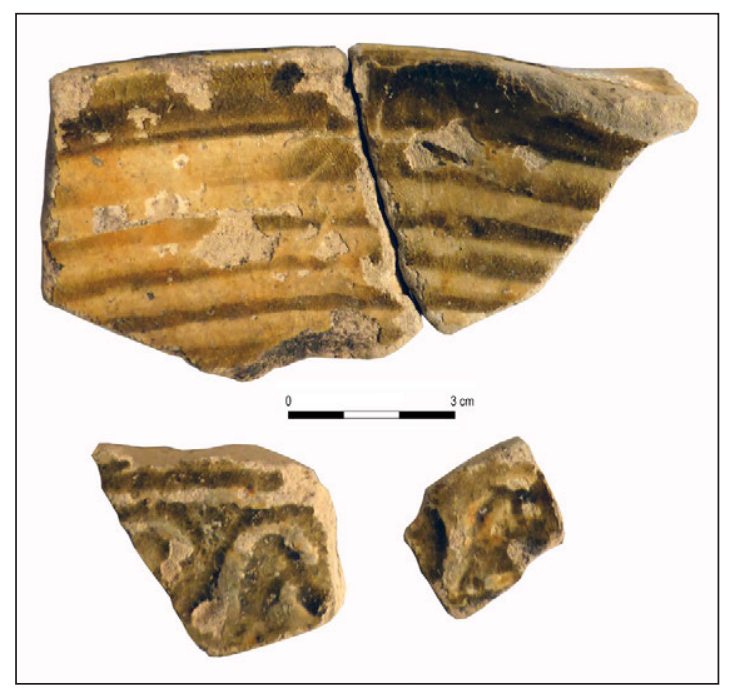

Figura 15. Fragmentos cerámicos vidriados correspondientes a una jarra (14.27.11.546-548).

\section{Monedas}

Se han encontrado dos pequeñas monedas de base cobre que apuntalan algunas de las apreciaciones cronológicas que venimos exponiendo.

De especial interés resulta el hallazgo en la superficie de la estructura 5 de un felús del tipo Frochoso IIa (peso 2,2 gr; diámetro máximo 15,2 mm), datado en el emirato dependiente (711-756), con la leyenda $N o$ dios si / no Dios en el anverso y Mahoma [es] el en / viado de Dios en el reverso (Frochoso 1996 y 2001)

La aparición de feluses del emirato dependiente en el valle del Ebro no es rara. Dejando a un lado el nutrido conjunto de ejemplares hallados en las intervenciones arqueológicas llevadas a cabo en los últimos años en los cascos urbanos de Zaragoza y Huesca, en su mayor parte todavía pendientes de publicación, cabe citar algunos hallazgos aislados en las inmediaciones de estas mismas ciudades, caso de Juslibol y 


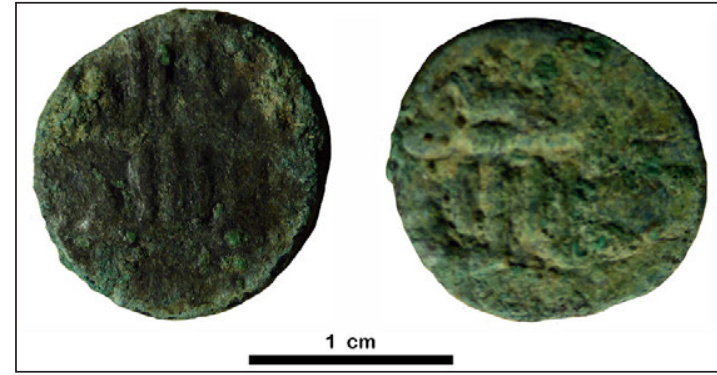

Figura 16. Felús localizado en superficie de la estructura $5 . \mathrm{N}^{\circ}$ inv. 14.27.05.578.

Pastriz (Lasa 1990: 253), cerca de la capital del Ebro, o los procedentes de los alrededores de Huesca (Domínguez et alii 1996). En contextos más periféricos, merece la pena mencionar el conjunto de 21 feluses hallados en La Mina (Selgua, Huesca) y el ejemplar documentado de forma aislada en Alcañiz (López Sánchez 1992; Lasa 1990: 254).

Además del inestimable valor cronológico de la moneda de Los Pedregales, coherente con los datos aportados por la cerámica, por un lado, y la datación radiocarbónica, por otro, el felús constituye un importante indicio del grado de penetración, a través de las acuñaciones monetarias, de la emergente administración islámica en medios claramente rurales del siglo vIII, hecho que contrasta con la marcada tendencia hacia el autoconsumo que evidencian los silos y las cerámicas de cocción reductora.

La otra moneda es un dinero moderno, probablemente una acuñación de Felipe IV de 1641 realizada en la ceca de Solsona. Se trata de un tipo, Crusafont 159, de acuñaciones relativamente corriente que se producen durante la Guerra dels Segadors (Crusafont 2001). Con apenas $0,7 \mathrm{gr}$ de peso y $14 \mathrm{~mm}$ de diámetro, presenta en el anverso busto del rey a izquierda con la leyenda CIVITAS * 16[4]1 y orla de puntos. En el anverso cruz patada con roeles en cuadrantes $1^{\circ}$ y $4^{\circ}$ y tres puntos en $2^{\circ}$ y $3^{\circ}$, leyenda $C O E-L S-O N-A$ terminando con dos puntos y orla de puntos.

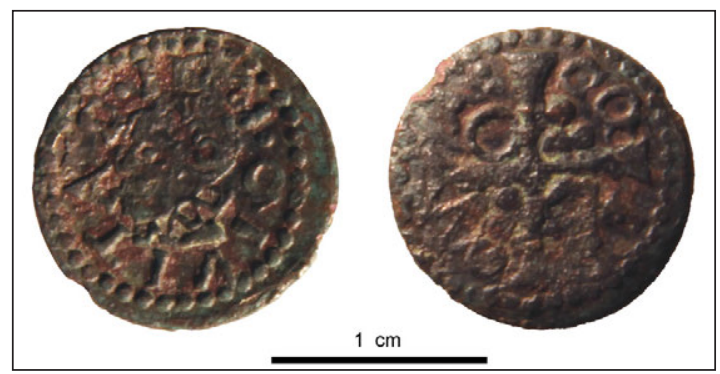

Figura 17. Dinero de Felipe IV encontrado en superficie. $\mathrm{N}^{\circ}$ inv. 14.27.579.
También procede de un contexto superficial, pero se encontraba bajo la capa superior que conforma el suelo actual, aparentemente desprendida de la misma, por lo que no guardaría relación con el campo de silos sino con los procesos erosivo-sedimentarios que afectan posteriormente a ese lugar.

\section{Restos óseos}

Resultan muy abundantes en superficie, donde se encuentran porciones de esqueletos en conexión anatómica. Por contra los restos estratificados en el interior de los silos, suelen ser huesos más o menos aislados, completos o fragmentados.

Aunque la muestra no resulta significativa por su pequeño tamaño y todavía se encuentra en fase de estudio (Sierra et alii 2015), se observan algunos aspectos que merece la pena reseñar, como el predominio de la fauna doméstica, sobre todo los huesos de oveja/cabra de diferentes edades que constituyen el grupo más representado. No hay selección de alguna parte del animal pues aparecen todas las porciones esqueléticas (craneal, axial y apendicular). En ocasiones presentan marcas de carnicería y de mordeduras de perros o zorros que como es norma tienden a concentrarse en las epífisis de los huesos largos (Fig. 18).

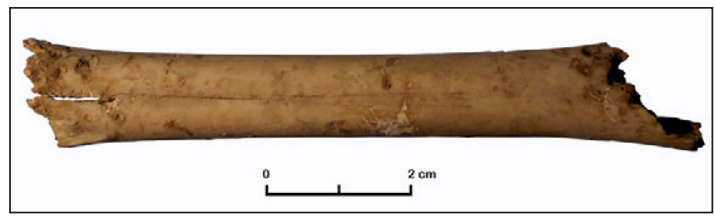

Figura 18. Metacarpo de Ovis/Capra con marcas de mordeduras en los extremos de la diáfisis. Estructura 2, UE 0203. $\mathrm{N}^{\circ}$ inv. 14.27.2.568.

Los bóvidos están presentes en todos los silos intervenidos. Se ha registrado un metacarpo (estructura 1), dos astrágalos en la estructura 3, uno más en la 5, con numerosas marcas de cortes, y tal vez un fragmento craneal con marcas de carnicería en la estructura 2 (Fig. 19). Además de estos restos fragmentarios, destaca parte de un esqueleto en conexión anatómica recuperado en la estructura 9, bajo las piedras superiores de la acumulación (Fig. 8). Se identifican las extremidades delanteras y caja torácica con costillas, esternón, parte de las vértebras y una pequeña porción de maxilar junto con fragmentos de piezas dentales de un ejemplar joven de Bos taurus. Tomando como referencia el grado de fusión de las epífisis (Habermehl 1975, Silver 1980, Grigson 1982) 


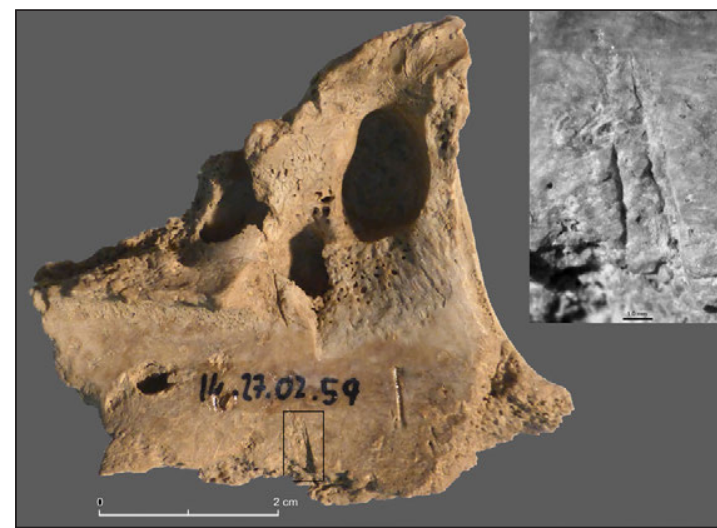

Figura 19. Fragmento craneal de mamífero grande, tal vez un bóvido, con marcas de carnicería. Estructura 2, UE 0203.

se puede estimar que se trata de un individuo en torno a los 12 y los 15 meses de edad.

Completan el conjunto pequeños huesos de conejo, un tarso-metatarso de ave, un fragmento de concha de molusco bivalvo y un caparazón casi completo de tortuga (Fig. 20), de unos $9 \mathrm{~cm}$ de longitud, sin otros huesos craneales o postcraneales, que debió incorporarse al depósito ya en esas condiciones.

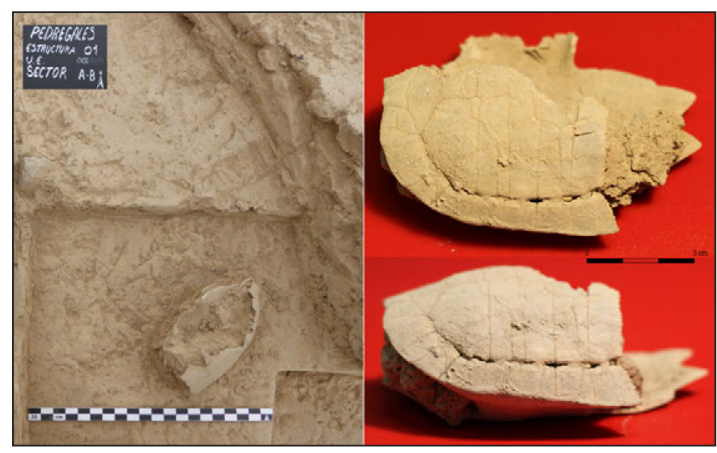

Figura 20. Caparazón de Mauremys leprosa procedente de la estructura 1, unidad 0102. $\mathrm{N}^{\mathrm{o}}$ inv. 14.27.1A.25.

Por tanto nos encontramos ante un conjunto dominado por bóvidos y ovicápridos. Este predominio, al menos desde el siglo viII, resulta recurrente por su diverso aprovechamiento, siendo más escasa la presencia de cerdos (Quirós 2009: 649) que, en el conjunto que presentamos, parecen estar ausentes. Seguramente el pequeño tamaño de la muestra condiciona esta apreciación, pero tampoco podemos perder de vista alguna práctica de tipo cultural o social que vincula el consumo de este animal a grupos de estatus elevado (Sirignano et alii 2014: 143). Asimismo, el predominio de individuos adultos, tanto en bóvidos como en ovejas y/o cabras, apunta a un aprovecha- miento de productos secundarios, práctica común en estos periodos.

Pero lo más significativo del limitado conjunto óseo es el hecho de que los restos recuperados en el interior de las estructuras negativas corresponden a desechos de consumo de animales habituales en las comunidades campesinas, como confirman las marcas de carnicería y la exposición al fuego de algunos fragmentos. Esos restos probablemente formaban parte de contextos tipo basurero, estuvieron expuestos a la intemperie durante cierto tiempo, lo que justifica las marcas de mordeduras de perros ${ }^{16} \mathrm{y} / \mathrm{o}$ zorros, así como los signos de meteorización, y se depositaron en el interior de los silos tras su abandono. La presencia de un esqueleto casi completo de una vaca joven (Fig. 8), no contradice la idea del uso de los silos, una vez amortizados, como vertederos incorporando no sólo basura doméstica sino también cadáveres de animales no aprovechados.

\section{LOS PEDREGALES Y LOS CAMPOS DE SILOS ALTOMEDIEVALES}

La presencia de campos de silos es un fenómeno generalizado en el contexto peninsular. Se conocen desde el Neolítico y son frecuentes en el Calcolítico, Edad del Bronce, Época Ibérica y Alta Edad Media. En Los Pedregales, las fechas obtenidas y los materiales asociados, remite a silos altomedievales de cronología visigoda e islámica, pero hay indicios que apuntan la posibilidad de perduraciones posteriores.

Los campos de silos son un tipo de yacimiento bien conocido, con numerosos ejemplos en el cuadrante NE peninsular, ya sea en las zonas más próximas de Huesca o Cataluña (Esco et alii 1988; Alonso et alii 2002; Roig 2013), en la provincia de Teruel (Herrero y Loscos 2010) y otros ámbitos del centro y norte peninsular (cfr. Fernández 1993; Quirós 2006; Folch 2005, Vigil-Escalera 2013a.

Estos campos reúnen un número muy variado de estructuras y, como en el caso de Los Pedregales, se ajustan a una cronología aparentemente prolongada ligada al mundo altomedieval. Su origen parece remontarse a época visigoda, con continuidad en época islámica y perduración en época cristiana ${ }^{17}$.

${ }^{16}$ Estudios isotópicos realizados sobre perros de yacimientos altomedievales de la provincia de Álava revelan un patrón alimenticio muy similar al humano, por lo que se deduce que fueron alimentados con desechos domésticos (Sirignano et alii 2014: 145), en la línea de lo observado en el conjunto de Los Pedregales.

${ }^{17} \mathrm{Su}$ inicio se documenta a partir de la segunda mitad del siglo V y, sobre todo, en el siglo VI tanto Cataluña (Ollich et 
En el área catalana se conocen algunos ejemplos que apuntan a ese origen tardoantiguo, caso de la villa de Aiguacuït, abandonada en el siglo vi, sobre la que se instala un conjunto de 14 silos y otras estructuras (Coll et alii 1997), el gran campo de L'Esquerda, con no menos de 66 silos datados entre los siglos $\mathrm{v}$ y VII, destinados al almacenaje de grano y rellenos de basura una vez amortizados (Ollich et alii 2012: 207) o los silos asociados al poblado visigodo del Bolavar, con final en los inicios del siglo viII (Palol 1986). Mención aparte para el área de Barcelona merece el caso de Can Gambús-1 (Roig 2013: 147-152), un gran asentamiento ex novo de inicios del siglo VI a finales del VIII, con 1,7 ha de extensión y en el que 233 de las 324 estructuras documentadas son silos. Estos aparecen repartidos por todo el yacimiento, algunos alineados, otros agrupados, pudiendo estar asociados a las estructuras superiores, entre las que se documentaron nueve recortes de cabaña.

Algunos ejemplos más tardíos se registran en la provincia de Teruel, donde se han estudiado varios campos excavados recientemente (Herrero y Loscos 2010), que denotan la perduración de estas estructuras hasta fechas relativamente avanzadas, como es el caso del campo localizado en la Calle de la Iglesia de Torrelacárcel, con 38 silos datados en los siglos XI y XII pero con una reutilización cristiana entre los siglos XIII y XV o el de la localidad de Fuentes Calientes, situado en una zona de huertas e integrado por 22 silos, con origen islámico en torno a los siglos $\mathrm{X}$-XI y perduración en época cristiana hasta su sellado definitivo en el siglo XV.

Las formas y dimensiones de estos silos también son relativamente variadas (cfr. Vigil-Escalera 2013a: 129). En el campo de Torrelacárcel (Teruel), donde se han encontrado los más completos, se observan tipos bitroncocónicos, troncocónicos o acampanados, cilíndricos y globulares (Herrero y Loscos 2010). Su tamaño es notable. En los esquemas reproducidos se puede estimar una altura que ronda los $2 \mathrm{~m}$ y fondos o diámetros máximos entre 1,50 y 2 m. Estas dimensiones se encuentran próximas a los límites máximos documentados en los silos de renta de Treviño (Quirós 2009: tabla 2) y están ligeramente por encima de las dimensiones estimadas para los supuestos silos de Los

alii 2012, Roig 2013) como en el País Vasco (Quirós 2013) y la zona centro (Vigil-Escalera 2013a). Hacia los siglos x y XI, los silos parecen más relacionados con la especulación y el almacenaje de rentas señoriales y alodios y diezmos eclesiásticos. Y finalmente durante la Baja Edad Media el almacenaje en silos va remitiendo en el contexto de la nueva economía feudal (Quirós 2013: 174). En la zona centro los silos desaparecen entre los siglos XIII-XIV en las zonas urbanas, mientras que pueden perdurar algo más en las zonas rurales (VigilEscalera 2013a: 142).
Pedregales ${ }^{18}$. En este sentido los silos de Los Pedregales se ajustarían más a capacidades en torno a los 25-30 hl, y, por tanto, parecen corresponder a silos "familiares" para las reservas anuales de la unidad doméstica, antes que silos destinados al almacenaje de rentas, cuyas capacidades parecen oscilar entre los 40 y 60 hl (cfr. Quirós 2009: 647-648).

Por lo que se refiere al contexto espacial, estos campos de silos suelen agruparse sin orden aparente y estar asociados a algún establecimiento de tipo rural. Son muchos los yacimientos donde las unidades domésticas y los silos comparten espacio, pudiendo estar alrededor de las casas, junto a ellas o incluso en su interior. Resultan muy ilustrativos casos como los grandes poblados de L'Esquerda, Bovalar (Coll et alii 1997) y Can Gambús-1 (Roig 2013: 147), las pequeñas aldeas de cabañas como Aiguacuït (Coll et alii 1997) y La Erilla (Quirós 2013: 177) o incluso la denominada "pre-aldea" datada entre los siglos VIIviII de Tossal de les Basses en Alicante, con los silos distribuidos en una especie de espacio central entre dos edificios rectangulares aislados, levantados con muros de piedra (Rosser 2014: 76). En otros yacimientos, como los estudiados en la provincia de Teruel, los silos no aparecen directamente relacionados con niveles y/o estructuras de habitación, aunque sí ponen de manifiesto la presencia de alguna comunidad en un entorno inmediato (Herrero y Loscos 2010: 154). En cualquier caso, la difícil detección y/o conservación de ciertas estructuras efímeras o poco relevantes ${ }^{19}$, muchas de ellas solo reconocibles por recortes y/o

\footnotetext{
${ }^{18}$ Los volúmenes estimados para los silos constituyen un dato relevante conectado con su significado económico y social. Un caso paradigmático que muestra la evolución en las capacidades de los silos a lo largo de la Edad Media es el que ofrece el yacimiento alavés de Zaballa, que abarca el periodo comprendido entre el siglo VI y el XVII (Quirós 2013: 177184). Durante su primera fase, siglos VI y VII, se documenta la presencia de silos de uso doméstico de unos 12 hl. En el siglo VIII hay una reorganización del paisaje, el sistema de aldeas estructura el tejido social y cobra gran importancia el almacenaje en silos. En este contexto, entre los siglos VIII y X, los silos Zaballa aumentan de tamaño alcanzando los 20-27 hl (dos casos excepcionales superan los $35 \mathrm{hl}$ ). En el siglo x la plataforma superior del yacimiento es ocupada por la iglesia de San Tirso y las unidades domésticas se desplazan al valle de Zaballa. Este cambio en la configuración urbana también se proyecta en la distribución del almacenaje: al noroeste de la iglesia se excavaron una serie de silos, uno de ellos con una capacidad calculada entre 54 y 63 hl. Se trataría de un silo para almacenar reservas, probablemente procedentes de rentas, controladas por una élite para su consumo propio y para alimentar a la población en caso de necesidad.

${ }^{19}$ Es frecuente que las estructuras de habitación, ya sean positivas o negativas, de los poblados altomedievales estén en mal estado de conservación o incluso desaparecidas por diferentes factores. Tal es así que Vigil-Escalera (2013a: 143) cifra en un $80 \%$ los yacimientos altomedievales de la Comunidad de Madrid que son conocidos gracias a sus silos.
} 
agujeros de poste, puede producir falsas impresiones y, tal vez, no sea un hecho tan excepcional la conexión en los mismos espacios de silos y construcciones tipo cabaña $^{20}$, conformando las estructuras habitacionales de pequeñas comunidades campesinas. En el caso que nos ocupa, los restos de basura doméstica en los rellenos y de un muro junto a los silos, parece revelar la existencia de un establecimiento rural de este tipo, lugar desde el que se explotaría el entorno inmediato en las márgenes del río Sotón, con un importante potencial cerealista. De hecho, la ubicación de Los Pedregales se corresponde bastante bien con la tendencia observada en otros asentamientos visigodos, como La Cuesta de la Calera o El Regollar, situados en llano, sobre terrazas con buenos suelos agrícolas en las proximidades del río Jalón, incluso junto a una vía pecuaria (Rodríguez 2014). Es un patrón que puede rastrearse en la ubicación de las villas tardorromanas y que parece tener continuidad en época islámica, coincidiendo con la localización que suelen presentar las almunias ${ }^{21}$, normalmente situadas en zonas bajas, planas y próximas de las zonas de irrigación (Sénac 1991: 399).

Pero tampoco podemos descartar que este campo de silos y el asentamiento asociado pueda estar ligado a alguno de los poblados conocidos en el entorno próximo, como el enclave denominado Valcorbera, un poblado en altura de cierta entidad, localizado $1,5 \mathrm{~km}$ al E de Los Pedregales. Se han identificado estructuras y materiales altomedievales sobre la cima de un destacado cerro, así como restos de un establecimiento romano anterior situado al pie del mismo, circunstancias que denotan la continuidad de la ocupación y la explotación de los mismos entornos desde época romana, pero una coyuntura social diferente marcada, entre otras circunstancias, por la inestabilidad.

\footnotetext{
${ }^{20}$ Este tipo de estructuras se identifican en los citados yacimientos de Aiguacuït (Coll et alii 1997) y Can Gambús-1 (Roig 2013: 147), así como en los recientes descubrimientos realizados en el valle del Jalón, en Cuesta de la Calera o El Regollar (Rodríguez 2014), yacimientos datados en época visigoda. Sin duda debieron configurar un tipo de asentamiento muy generalizado pero mal conocido por la escasa visibilidad de sus restos.

${ }^{21}$ A pesar de las prevenciones que plantea Laliena para la distinción de este tipo de hábitat rural respecto a otros como pueden ser las alquerías por lo difuso de sus límites (Laliena 2010: 40), no podemos obviar que cerca de Los Pedregales se cita la almunia de Alboreg, situada junto al pantano de la Sotonera con una cronología en torno a 1100 d. C., y que debió ser un tipo de asentamiento relativamente frecuente, que llega a alcanzar cierta densidad en algunas zonas, como en el caso de Monzón (Huesca), en cuyo entorno documentos de fines del siglo XI d. C. recogen varias decenas de ellas (Sénac 1991: 399).
}

Cualquiera que sea el caso, el campo de silos de Los Pedregales parece el resultado acumulativo a lo largo de varios siglos del uso y amortización de silos por parte de una comunidad campesina formada por unas pocas unidades domésticas, que tratan de proteger y gestionar sus recursos en el contexto de nuevas estrategias económicas, tanto productivas como para la gestión del almacenaje (Vigil-Escalera 2013a: 141). En este sentido, el yacimiento se integraría en un paisaje agrario formado por pequeñas comunidades dispersas en este sector de la Hoya de Huesca, que reproducen la ocupación tradicional, heredada de época romana, tras la desarticulación del sistema socio-económico antiguo, aprovechando el potencial cerealista de la zona y apoyadas en la explotación de cabañas ganaderas en las que parecen tener un especial peso los rebaños de ovejas-cabras y el ganado vacuno. Este tipo de asentamientos rurales, abiertos y en llano constituirá, el sustrato básico del sistema de poblamiento jerarquizado que se impone entre los siglos v al Ix, en cuya cúspide se encuentra la ciudad, y que cuenta con un escalón intermedio formado por una amplia variedad de asentamientos encastillados (Vigil-Escalera 2013b: 207).

\section{LOS PEDREGALES Y EL POBLAMIENTO TAR- DOANTIGUO E ISLÁMICO EN LA HOYA DE HUESCA}

Esas consideraciones sobre el yacimiento de Los Pedregales se perciben al valorar algunos datos del poblamiento de este sector de la Hoya de Huesca derivados de intervenciones clandestinas ${ }^{22}$, de informaciones documentales y de prospecciones arqueológicas.

A pesar de la escasez y parcialidad de las investigaciones, tenemos algunas certezas como es la presencia significativa de asentamientos rurales de cronología romana con origen en época alto imperial y perduración hasta el Bajo Imperio. La carencia de estudios exhaustivos sobre el periodo nos impiden determinar la naturaleza de los diferentes sitios, ya sean pequeñas granjas, villas de tamaño medio o incluso establecimientos mayores, como la población de Calagurris Fibularia, citada por las fuentes latinas y medievales y cuya ubicación desconocemos, aunque se viene situando en las inmediaciones de

\footnotetext{
${ }^{22}$ Desde mediados del siglo xx hay constancia de frecuentes acciones fuera del ámbito legal en enclaves que han aportado interesantes elementos metálicos de los que hemos tenido noticias muy imprecisas, como las referidas al jarrito litúrgico de Puibolea (Esco 1990: 67), piezas singulares que, solo en contadas ocasiones y tras complicadas peripecias, han pasado a engrosar los fondos del Museo de Huesca.
} 
Bolea (Esco y Sénac 1987: 150-151). Enclaves como el Torreón (Paz y Sánchez 1984: 193-257), Lugaré (Biscarrués), Castillo de Artasona (Castán 2004: 97), La Corona (Bolea) (Esco y Sénac 1987: 150), Castillón (Puibolea) (Esco y Sénac 1987: 150), Puypullín (Loscorrales) (Guart 1985), El Villar (Lupiñén), son asentamientos cuyo hábitat se inicia en época alto imperial con perduración en siglos posteriores. A ellos se les une un largo listado de hallazgos menores y sin estudios específicos, que formarían parte de la retícula de establecimientos rurales que cultivan las productivas tierras de este territorio. Todos estos enclaves nos permiten entrever, a partir del siglo II d. C., un paisaje antropizado, producto de la explotación agraria de las fértiles tierras de la Sotonera.

Los cambios políticos, económicos y culturales que se suceden entre los siglos v y XI, a la fuerza tuvieron que influir en la población de esta área, pero resulta muy complicado analizar, a través del registro arqueológico conocido, esta evolución salvo en lo que concierne a la dinámica del poblamiento. Hasta el siglo $\mathrm{V}$, el hábitat está concentrado en asentamientos situados en el terreno llano, sobre elevaciones escasamente destacadas, pero a partir de los siglos V-VI surgen nuevos emplazamientos en alto, de carácter defensivo, que se distribuyen en el entorno de Huesca y Bolea (Esco y Sénac 1987). Como ejemplo podemos citar la parte superior de Castillón (Puibolea) o Valcorbera (Lupiñén-Almudévar). Este cambio no supondrá necesariamente la desaparición de los enclaves del llano, como pone de manifiesto el propio yacimiento de Los Pedregales, sino que convivirán ambos modelos, configurando ese poblamiento dual, aparentemente jerarquizado, que comentábamos anteriormente y que perdurará durante los primeros tiempos de ocupación islámica, siendo, estas comunidades mozárabes las responsables de la explotación agrícola del territorio (Esco y Sénac 1987: 151).

A partir del siglo VIII contamos con las aportaciones del trabajo de $\mathrm{Ph}$. Sénac (2000) en el que recoge los establecimientos rurales del entorno de Huesca citados en las fuentes. Entre otros, se mencionan lugares como las villas de Ayerbe, Bolea o Puibolea, además de almunias como la de Alboreg (Sénac 2000: 233-234, 252-255). Sería interesante poder documentar arqueológicamente estos lugares pero, aunque no tengamos este contraste, la referencia a estos pequeños establecimientos rurales a lo largo de los siglos X-XI evidencia una ocupación del territorio relativamente densa. En relación con ello, otro fenómeno importante que corrobora la entidad de ese poblamiento disperso y la importancia agraria y estratégica de este territorio es el gran esfuerzo que se realizó en la construcción de una red de torres defensivas que protegían esta rica franja fronteriza. El listado de torres es amplio y seguro que aumentaría en el caso de que se realizaran trabajos sistemáticos de prospección arqueológica: Lierta (Almudévar) (Castán 2004: 73), Torre Trinidad Bolea (Castán 2004: 149), Samitiel (Castán 2004: 351; Galtier 1987) y la Atalaya de Tormos (Galtier 1987: 179-185; Castán 2004: 404-407). A los que podríamos añadir las posibles torres del castillo de Artasona, atalaya Rosel, castillo de Becha...

Así, en época altomedieval, podríamos diferenciar dos momentos en lo que se refiere a la forma en la que la población habita y explota el área. Inicialmente, siglos VI-IX, la población se distribuye en pequeños establecimientos rurales en el llano a la vez que surgen una serie de poblados en altura que denotan inestabilidad y en los que prevalece la idea de defensa y control de los entornos próximos, sin que se aprecien cambios significativos tras la conquista islámica, en las primeras décadas del siglo VIII o incluso en el siglo IX. A partir de los siglos $\mathrm{X}$-XI, de nuevo se impone el hábitat en el llano en lugares muy próximos a los antiguos asentamientos romanos. Sin duda esta coincidencia obedece a varios factores, entre los que destacamos el hecho de que se trata de los lugares más favorables (cultivos, agua, comunicaciones...) y la posibilidad de reaprovechar los materiales constructivos procedentes de los arruinados asentamientos romanos en las nuevas construcciones medievales. Estos asentamientos del llano se ven reforzados y protegidos por un nuevo tipo de construcción defensiva, las torres. Su función se limita al control del territorio e implica la existencia de una autoridad efectiva de tipo supracomunitario que ordena y gestiona el territorio, reflejando, ahora sí, un cambio significativo con relación a la estructura económica y social de la etapa anterior.

\section{CONCLUSIONES}

En primer lugar hay que destacar que el yacimiento de Los Pedregales es un conjunto sumamente transformado para cuya interpretación ha sido necesario un análisis geoarqueológico a partir del cual ha sido posible deducir que corresponde a un campo de silos de cierta extensión. La apariencia actual de un espacio acarcavado, jalonado de concentraciones de piedras no es sino el resultado de los procesos erosivos que han modificado el yacimiento, desmantelando la antigua superficie, incidiendo sobre las arcillas y limos del sustrato donde se han excavado los silos y dejando expuestos sus rellenos, más consistentes, que adquieren el aspecto de estructuras tumulares al estar coronadas por acumulaciones pétreas. A su 
vez, la erosión acelerada que afecta a este sector está resultando catastrófica, provocando el rápido desmantelamiento de las diferentes estructuras y la dispersión de sus materiales.

Independientemente de la presencia de materiales romanos superficiales, la ocupación principal es altomedieval y está representada por el campo de silos. Las dataciones obtenidas apuntan a una cronología de los siglos VI y viI que pueden marcar los momentos iniciales, si bien a nivel peninsular comienzan a documentarse a partir del siglo $\mathrm{v}$, tanto en la zona centro (Vigil-Escalera 2013a: 141), como en yacimientos catalanes (Ollich et alii 2012). A su vez, dentro de esos silos, las pocas cerámicas que aparecen son bastante uniformes: cerámicas a torno-mano, grises, relativamente toscas con intrusiones puntuales de cerámicas a torno oxidantes. Este tipo de producciones tanto en yacimientos aragoneses, como levantinos o catalanes suelen vincularse a periodos tardoantiguos o paleoislámicos, alrededor de los siglos V-IX, por lo que la cronología del campo de silos, en sintonía con las fechas obtenidas, podría llevarse a época visigoda con extensión a época emiral, anterior al siglo x. No obstante, por toda la zona abundan las cerámicas a torno oxidantes de cronología islámica y posterior, por lo que podemos pensar que la ocupación continúa en los siglos X-XI, e incluso en el siglo XIII, por la presencia de producciones cristianas vidriadas. Pero de nuevo debemos tener en cuenta que algunas de esas cerámicas pueden proceder de otros contextos próximos pues aparecen estratificadas en la acumulación superior que configura la superficie actual, un cono de deyección que incorpora materiales finos y medios y con ellos restos cerámicos derivados de su ubicación original. Con la erosión de esa superficie y el depósito que la soporta, las cerámicas terminan de dispersarse por todo el yacimiento, contribuyendo a conformar esa imagen bastante confusa del mismo.

De acuerdo con la cronología central y el tipo de estructuras documentadas podemos plantear la hipótesis de que nos encontramos ante un pequeño establecimiento rural y un campo de silos asociado que se fue formando en un proceso acumulativo a lo largo de un periodo de tiempo de varios siglos a través de sucesivos usos, reutilizaciones y amortizaciones de los graneros subterráneos. Este tipo de establecimientos parece ser una herencia residual del sistema de villae de época romana, que plasman la transformación de una economía integrada y dirigida, en formas de producción básicamente domésticas, conformando una red de pequeñas comunidades campesinas básicamente autosuficientes en lo que se refiere al aprovisionamiento de recursos básicos agrícolas y ganaderos (cfr. Sirignano et alii 2014:
146), relativamente dispersas y formadas por unas pocas unidades familiares, lo que no significa comunidades cerradas, más o menos aisladas en una especie de autarquía productiva. Este cambio queda bien reflejado en las producciones cerámicas ligadas al ámbito doméstico, en la gestión de la producción y, como se viene repitiendo, va asociado a un clima de cierta inestabilidad, lo que potencia el establecimiento de estos campos de silos como forma de ocultar y proteger los recursos del grupo, así como el desarrollo de ocupaciones en altura donde se instalaría otra parte de la población.

Ambos tipos de asentamiento, los pequeños establecimientos en llano, abiertos y directamente localizados en las zonas de elevado potencial productivo, junto con poblados en altura de cierta entidad, que proporcionan seguridad y desde los que se ejerce cierto control sobre el territorio inmediato, configurarían un tipo de poblamiento dual, dentro de un modelo jerarquizado cuya cúspide sería la ciudad, que es perfectamente reconocible en la Hoya de Huesca y que, en líneas generales, parece que es el que se impone en otros ámbitos peninsulares (Vigil-Escalera 2013b: 207).

En los procesos de transformación que parecen experimentar estas comunidades domina la continuidad. Tras la desarticulación del "modelo romano", las formas sociales que se imponen a lo largo de los siglos V, VI y VII se mantienen relativamente estables, pero incluso, tras la conquista islámica, desde la perspectiva actual, no parece que experimenten cambios relevantes. Ahora bien, sobre estas mismas comunidades campesinas, a pesar de su pequeño tamaño, descansa el desarrollo agrario subsiguiente. Continúan ocupando espacios muy productivos en los que parece apreciarse un proceso expansivo y una transición desde la relativa autogestión, al control progresivo de las élites, mucho más centralizado, que se plasma por la generalización de las torres de vigilancia a partir de fechas algo más avanzadas, en torno a los siglos X-XI, tal vez vinculadas con los cambios y el mayor control que ejerce el estado islámico tras el establecimiento del emirato independiente.

\section{AGRADECIMIENTOS}

Queremos expresar nuestra gratitud a diferentes entidades y personas que nos han ayudado a sacar adelante este trabajo. En primer lugar al Ayuntamiento de Lupiñén-Ortilla por las facilidades proporcionadas para la realización de la excavación. A los arqueólogos Jonathan Terán y Alejandro Martín de la Universidad de Zaragoza y a la estudiante de Geografía María 
Royo, también de la Universidad de Zaragoza, por su inapreciable ayuda en la excavación y topografía del yacimiento. Al arqueólogo Alejandro Sierra y a la Dra. Fernanda Blasco, por sus importantes aportaciones relacionadas con los restos óseos. A Marta Alcolea, antracóloga, por la clasificación de carbones objeto de datación. Por último a la Dra. Natalia Alonso de la Universidad de Lleida, quien amablemente nos facilitó la imagen del Vilot de la Figura 9.

\section{BIBLIOGRAFÍA}

Alba Calzado, M. y Gutiérrez Lloret, S. 2008: "Las producciones de transición al Mundo Islámico: el problema de la cerámica paleoandalusí (siglos VIII y IX)", D. Bernal Casasola y A. Ribera i Lacomba (eds.), Cerámicas hispanorromanas. Un estado de la cuestión, Cádiz, 585-613.

Alonso, N., Gené, M., Junyent, L., Lafuente, A., López, J. B., Moya, A. y Tartera, E. 2002: L' assentament protohistòric, medieval i d'època moderna de El Vilot de Montagut (Alcarràs, Lleida), Barcelona

Arthur, P. 2006: "Form, Function and Technology in Pottery Production from Late Antiquity to the Early Middle Ages", L. Lavan, E. Zanini y A. Sarantis (eds.), Technology in Transition, A.D. 300-650, Leiden-Boston, 159-186.

Arthur, P. 2007: "Pots and Boundaries. On Cultural and Economic Areas between Late Antiquity and the Early Middle Ages", LRCW 2. Late Roman Coarse Wares, Cooking Wares and Amphorae in the Mediterranean: Archaeology and Archaeometry, Oxford, 15-28.

Asensio Esteban, J. A. y Magallón Botaya, M. A. 2011: La fortaleza altomedieval del Cerro del Calvario, en la Puebla de Castro: Un hisn en el extremo norte de la Marca Superior de alAndalus, , Huesca.

Azkárate, A. y Quirós Castillo, J.A. 2001: “Arquitectura doméstica altomedieval en la Península Ibérica. Reflexiones a partir de las excavaciones arqueológicas de la Catedral de Santa María de Vitoria-Gasteiz, País Vasco", Archeologia Medievale XXVIII, 25-60.

Badía, D., Cuchí, J. A., Ibarra, P., Longares, L. A., Macías, F., Martí, C., Peña, J. L., Pérez. C., Poch, R. M., Romero, D., Sancho, S., Saz, M. A. y Silva, J. 2009: Itinerarios edáficos por el Alto Aragón, Cuadernos Altoaragoneses de Trabajo n 28 , , Huesca.

Castán Sarasa, A. 2004: Torres y Castillos del Alto Aragón, , Huesca.
Cau, M. A., Giralt, J., Macías, J. M., Padilla, J. I. y Tuset, F. 1997: "La cerámica del Nordeste peninsular y las Baleares entre los siglos V-X", La céramique médiévale en Méditérranée. Actes du 6e-Ccongrès, Aix-en-Provence, 173-192.

Coll Conesa, J. y García Porras, A. 2010: “Tipología, cronología y producción de los hornos cerámicos en al-Andalus", Arqueología Medieval, http:// www.arqueologiamedieval.com/articulos/125/ tipologia-cronologia-y-produccion-de-los-hornosceramicos-en-al-andalus

Coll Riera, J. M., Roig i Buxó, J. A., Molina i Vallmitjana, J. A. 1997: "Las producciones cerámicas de época visigoda en la Catalunya Central (ss.VVII): consideraciones técnicas y morfológicas", La céramique médiévale en Méditérranée. Actes du 6e Congrès, Aix-en-Provence, 193-197.

Constante, A., Peña, J. L., Muñoz, A. y Picazo, J. 2011: "Climate and Anthropogenic Factors Affecting Alluvial Fan Development during the Late Holocene in the Central Ebro Valley, Northeast Spain", The Holocene 21, 2, 275-286, http:// dx.doi.org/10.1177/0959683610378873

Crusafont, M. 2001: Història de la moneda de la Guerra dels Segadors. Primera República Catalana. 1640-1652, Barcelona.

Domínguez Arranz, A., Escudero Escudero, F. A. y Lasa Gracia, C. 1996: El patrimonio numismático del Ayuntamiento de Huesca, Huesca.

Esco Sampériz, C. 1990: "La antigüedad tardía (siglos IV-VII)", C. Laliena (coord.), Huesca. Historia de una ciudad, Huesca

Esco Sampériz, C., Giralt, J. y Sénac, Ph. 1988: Arqueología islámica en la Marca Superior de alAndalus, Huesca.

Esco Sampériz, C. y Sénac, Ph. 1987: "Bolea (Huesca): una fortaleza de la marca superior de AlAndalus", Bolskan 4, 147-174.

Fernández Ugalde, A. 1993: "El fenómeno del relleno de silos y la implantación del feudalismo en Madrid y en el reino de Toledo", IV Congreso de Arqueología Medieval Española, 3, Alicante, 611-617.

Folch Iglesias, C.: 2005: "La cerámica de la Alta Edad Media en Cataluña (S. VIII-IX d. C.): el estado de la cuestión", Arqueología y Territorio Medieval 12, 2, 237-254. http://dx.doi.org/10.17561/aytm. v12i2.1715

Frangin, E., Koenig, M. P., Naton, H. G., Prouteau, R., Galland, S., Decanter, F., et Wiethold, J. 2014: "Une succession d'habitats ruraux médiévaux (Vie-XIIe siècle) sur la commune de Les TroisDomaines (Lorraine, Meuse)", Revue Archéologique de l'Est 63, 337-412. 
Frochoso Sánchez, R. 1996: "Los feluses de los gobernadores omeyas de al-Andalus", Numisma 237, 259-289.

Frochoso Sánchez, R. 2001: Los Feluses de al-Andalus, Córdoba.

Galtier Martí, F. 1987: “El verdadero castillo de Samitier", Turiaso VII, 159-194.

Galve Izquierdo, P. 1988: “Aproximación al estudio de la cerámica de época emiral en la ciudad de Zaragoza", Caesaraugusta 65, 235-261.

Grigson, C. 1982: "Sex and Age Determination of Some Bones and Teeth of Domestic Cattle: a Review of the Literature", B. Wilson, C. Grigson and S. Payne (eds.), Ageing and sexing animal bones from archaeological sites, BAR British Series 109, 7-23.

Guart, I.M. 1985: "Los materiales arqueológicos de Puypullín, Loarre (Huesca)", Bolskan 2, 153-166.

Gutiérrez González, F.J. y De Miguel Millán, C. 2010: "La cerámica del arrabal meridional de Zaragoza durante la Edad Media”, J. Ortega y C. Escriche (eds.), Actas I Jornadas de Arqueología Medieval en Aragón. Balances y novedades, Teruel, 427459.

Gutiérrez Lloret, S. 1986: “Cerámicas comunes altomedievales: contribución al estudio del tránsito de la Antigüedad al mundo paleoislámico en las comarcas meridionales del País Valenciano", Lucentum 5, 147-167. http://dx.doi.org/10.14198/ lvcentvm 1986.5.09

Habermehl, K. H. 1975: Die Altersbestimmung bei Haus- und Labortieren 2. vollständig neubearbeitete Auflage. Berlin and Hamburg.

Hernández Vera, J. A y Bienes Calvo, J. J. 2003: "Cerámicas hispano visigodas y de tradición en el Valle Medio del Ebro", L. Caballero, P. Mateos y M. Retuerce (eds.), Cerámicas tardorromanas y altomedievales en la Península Ibérica, Anejo de Archivo Español de Arqueología XXVIII, Madrid, 307-319.

Herrero Gascón, M. A. y Loscos Pastor, R. M. 2010: "Silos, alfares y metalurgia: sistemas de producción en el mundo rural andalusí del sur de Aragón”, J. Ortega y C. Escriche (eds.), Actas I Jornadas de Arqueología Medieval en Aragón. Balances y novedades (Teruel, julio 2006), Museo de Teruel-Instituto de Estudios Turolenses, Teruel, 135-155.

Laliena Corbera, C. 2010: “Arqueología del poblamiento en el Aragón Medieval (siglos X-XIII): problemas de historia social", J. Ortega y C. Escriche (eds.), Actas I Jornadas de Arqueología Medieval en Aragón. Balances y novedades, Teruel, 29-52.
Lasa Gracia, C. 1990: "Hallazgos numismáticos de época islámica: Alcañiz y Zaragoza”, II Jarique de Numismática Hispano-Árabe, Lérida, 249-257.

López Sánchez, P. 1992: "La circulación del numerario árabe en la comarca de Monzón", Gaceta Numismática 105-106, 165-178.

Morris, J. 2011: Investigating Animal Burials. Ritual, Mundane and Beyond, British Series 535. BAR, Oxford.

Ollich, I., Rocafiguera, M., Ocaña, M., Cubero, C. y Amblàs, O. 2012: "Experimental Archaeology at L'Esquerda - Crops, Storage, Metalcraft and Earthworks in Mediaeval and Ancient Times", I. Ollich (ed.), Archaeology, New Approaches in Theory and Techniques, Rijeka (, 205-228. http:// dx.doi.org/10.5772/38790

Palol, P. de 1986: "Las excavaciones del conjunto de "El Bolavar", Serós (Segriá, Lérida) y el reino de Akhila”, Antigüedad y cristianismo: Monografías históricas sobre la Antigüedad Tardía, 3, 513-526.

Paz Peralta, J., Ortiz Palomar, M. E. y Viladés Castillo, J. M. 1992: "Estudio de materiales del yacimiento altomedieval de El Corral de Calvo (Luesia, Zaragoza)", Arqueología Aragonesa 1990, Zaragoza, 137-142.

Paz Peralta, J. y Sánchez Nuviala, J. J. 1984: "Una villa romana en el Torreón (Ortilla, Huesca)", Boletín del Museo de Zaragoza 3, 193-257.

Quirós Castillo, J. A. 2006: "La génesis del paisaje medieval en Álava: la formación de la red aldeana", Arqueología y Territorio Medieval 13, 1, 49-94. http://dx.doi.org/10.17561/aytm.v13i1.1519

Quirós Castillo, J. A. 2009: "Arqueología de los espacios agrarios medievales en el País Vasco", Hispania. Revista Española de Historia, LXIX, 233, 619-652. http://dx.doi.org/10.3989/hispania.2009. v69.i233.115

Quirós Castillo, J. A. y Vigil-Escalera, A. 2006: "Networks of Peasant Villages between Toledo and Velegia Alabense, Northwestern Spain (V-Xth centuries)", Archeologia Medievale XXXIII, 79-128.

Ramón Fernández, N. 2013: "La vajilla del convento de San Francisco de Zaragoza", N. Ramón, A.I. Lapeña y A. Serrano (eds.), Entre sextas y vísperas. La mesa en un convento medieval de Zaragoza, Zaragoza, 14-25.

Rodríguez Cifuentes, M. 2014: "La Alta Edad Media", M. Rodríguez Cifuentes (dir.), Formación e intercambio cultural en el Alto Jalón, Madrid, 319-346.

Roig Buxó, J. 2013: "Silos, poblados e iglesias: almacenaje y rentas en época visigoda y altomedieval en Cataluña (siglos VI al XI)", A. Vigil-Escalera, G. Bianchi y J.A. Quirós (eds.), Horrea, Barns 
and Silos. Storage and Incomes in Early Medieval Europe, Documentos de Arqueología Medieval, 5, Vitoria, 145-170.

Rosser Limiñana, P. 2014: “Arqueología del poblamiento de un territorio del Mediterráneo occidental (Alicante, España) en época tardo-antigua. Un espacio activo sin ciudad", Anales de Prehistoria y Arqueología, 30, 55-38.

Salvatierra Cuenca, V. 2015: "El lugar de visigodos y omeyas en la historiografía de los siglos XIX y XX. Aportaciones a un debate sobre continuidad y ruptura", Archivo Español de Arqueología 88, 247 261. http://dx.doi.org/10.3989/aespa.088.015.013

Sénac, Ph., 1991: "Poblamiento, hábitats rurales y sociedad en la marca superior de Al-Andalus", Aragón en la Edad Media 9, 389-402.

Sénac, Ph. 2000: La frontière et les hommes (VIIIXII siècle). Le peuplement musulman au nord de l'Ebre et les debuts de la reconquête aragonaise, Paris.

Sierra Sainz-Aja, A., Pérez Lambán, F. y Picazo Millán, J. V. 2015: "Estudio de los restos faunísticos de los silos altomedievales de Los Pedregales (Lupiñén-Ortilla, Huesca)", póster I Congreso de Arqueología y Patrimonio Aragonés, Zaragoza.

Silver, I. A. 1980: "XXVI. La determinación de la edad en los animales domésticos", D. Brothwell y E. Higgs (comps.), Ciencia en Arqueología, Madrid, 289-309.

Sirignano, C., Grau, I., Ricci, P., García-Collado, M. I., Altieri, S., Quirós, J. A. y Lubritto, C. 2014: "Animal Husbandry during Early and High Middle Ages in the Basque Country (Spain)", Quaternary International 346, 138-148. http://dx.doi. org/10.1016/j.quaint.2014.05.042

Travé Allepuz, E. y Padilla Lapuente, J. I. 2013: “Alfares, hornos y producción de cerámica en la Cataluña Medieval y Moderna: una reflexión para su estudio", Territorio, Sociedad y Poder 8, 105-132.

Triay Olives, V. 2012: "La ocupació altmedieval de la Vilanova dels Arcs Vells", Quarhis 8, 112-129.

Vigil-Escalera, A. 1999: "Evolución de los morfotipos de cerámica común de un asentamiento rural visigodo de la Meseta (Gózquez de Arriba, San Martín de la Vega, Madrid)", Revista Arqueohispania 0, http://studylib.es/doc/355140/evoluci\%C3\%B3nde-los-morfotipos-de-cer\% C $3 \%$ A 1 micacom\%C3\%BAn-de-un-asent...

Vigil-Escalera, A. 2013a: "Ver el silo medio lleno o medio vacío: la estructura arqueológica en su contexto", A. Vigil-Escalera, G. Bianchi y J. A. Quirós (eds.), Horrea, Barns and Silos. Storage and Incomes in Early Medieval Europe, Documentos de Arqueología Medieval, 5, Vitoria, 127-144.

Vigil-Escalera, A. 2013b: "Espacio social y espacio doméstico en los asentamientos campesinos del centro y norte peninsular (siglos V-IX d. C)", S. Gutiérrez Lloret e I. Grau Mira (eds.), De la estructura doméstica al espacio social. Lecturas arqueológicas del uso social del espacio, Alicante, 207-222.

Vroom, J. 2009: "Medieval Ceramics and the Archeology of Consumption in Medieval Anatolia", T. Vorderstrasse y J. Roodenberg (eds.), Archaeology of the Countryside in Medieval Anatolia, Leiden, 235-258.

Wickham, C. 2005: Framing the Early Middle Ages: Europe and the Mediterranean 400-800, Oxford University Press, Oxford.

Recibido: 26-06-2015

Aceptado: 01-12-2015 